\title{
Assessing behavioural and social
} responses to an eco-mooring trial for

\section{Zostera marina conservation}

\section{management in Torbay, Southwest England}

Parry-Wilson, HM

http://hdl.handle.net/10026.1/14811

10.1016/j.ocecoaman.2019.104906

Ocean and Coastal Management

Elsevier

All content in PEARL is protected by copyright law. Author manuscripts are made available in accordance with publisher policies. Please cite only the published version using the details provided on the item record or document. In the absence of an open licence (e.g. Creative Commons), permissions for further reuse of content should be sought from the publisher or author. 
Parry-Wilson et al. Assessing behavioural and social responses to an eco-mooring trial for Zostera marina conservation management in Torbay, Southwest England.

1 Assessing behavioural and social responses to an eco-mooring trial for Zostera

2 marina conservation management in Torbay, Southwest England

Hannah M. Parry-Wilson ${ }^{1 \dagger}$, Sian E Rees ${ }^{1}$, Harrison Leather ${ }^{1}$, Rachel Cole ${ }^{2}$, Clare Rugg ${ }^{3}$ \& Martin J Attrill ${ }^{1}$

1 School of Biological and Marine Science, University of Plymouth, Drake Circus, Plymouth, PL4 8AA.

${ }^{2}$ Community Seagrass Initiative, National Marine Aquarium, Rope Walk, Coxside, Plymouth PL4 OLF.

${ }^{3}$ Living Coasts, Torquay Harbourside, Beacon Hill, Torquay TQ1 2BG.

8

† Corresponding Author: hanwil@mba.ac.uk; Marine Biological Association, The Laboratory, Citadel Hill, Plymouth PL1 2PB

Key Words: Seagrass; eelgrass; environmental impact; MPA; VNAZ; seagrass-friendly; questionnaire; anchoring; boat mooring; recreation

\section{Abstract}

Seagrass beds are critically important habitats delivering a range of ecosystem service benefits that support human wellbeing. They are, however, declining globally at an unprecedented rate. The damaging effects on Zostera marina (Common Eelgrass) seagrass beds in UK waters from mechanical recreational boating activities, namely anchoring and traditional swing mooring scour, suggest that measures of implementing management to mitigate human impacts need prioritising. Ecomoorings, a design that reduces the abrasion pressure of anchoring and mooring on the seabed, are such a mitigation method. In the UK, limited test sites and a lack of social acceptance of the technology compounds the limited uptake of eco-moorings to date. To advance the evidence base, this study focusses on a bespoke eco-mooring design deployed in 2017 to protect seagrass beds within a popular anchorage in Southwest England. We assess the behavioural and social responses of recreational boaters to the trial eco-mooring through 1) mapping of boating activity pre- and postdeployment and 2) structured questionnaires both on-site and online to local and national audiences respectively. Results of mapped boating activity demonstrated a shoreward distribution shift of anchoring away from the deployed eco-mooring, with $45.4 \%$ of all anchoring vessels directly within or within a range of potential influence of the seagrass bed. Through the deployment of the eco-mooring (where no mooring previously existed), an estimated additional $20 \%$ of anchoring pressure was alleviated from the seagrass bed. A total of $89.6 \%$ of on-site respondents reacted positively to the prospect of further eco-moorings being deployed locally. When questioned, $74.6 \%$ of on-site and $82.8 \%$ of online respondents demonstrated a preference for the physical 
Parry-Wilson et al. Assessing behavioural and social responses to an eco-mooring trial for Zostera marina conservation management in Torbay, Southwest England.

moorings in seagrass-dense regions could successfully alleviate anchor damage, especially where over half of respondents indicated an awareness of seagrass presence prior to anchoring their vessel and/or hesitance to cease visiting preferential anchoring sites (sheltered bays). This study recommends targeting conservation guidance at the powerboat community, the dominant group anchoring/mooring in the study area and identified as not currently engaged in seagrass education campaigns. It is proposed that management introduce incentives such as free of charge ecomoorings and/or anchoring charges in Marine Protected Areas/Voluntary No Anchor Zones to conserve and recover seagrass and other sensitive seabed habitats nationally.

\section{Introduction}

One of two seagrass species found in the UK, Zostera marina (Common Eelgrass) is a marine flowering plant (Davison and Hughes, 1998) found in sheltered subtidal and intertidal zones at flow velocities below $1.5 \mathrm{~m} / \mathrm{s}$, down to depths of 10-15 m dependent on water clarity (Borum et al., 2004; Hemminga and Duarte, 2000; Jackson et al., 2013). Z. marina is recognised as providing a critical functional role in the delivery of beneficial ecosystem services. For example, with roots and horizontal rhizomes located to a maximum $20 \mathrm{~cm}$ depth (Davison and Hughes, 1998), stabilisation of sediments secures long-term carbon burial to store $12-20 \%$ of global oceanic 'blue carbon' (Borum et al., 2004; Commission for Environmental Cooperation, 2016). As well as displaying significantly more biodiversity than that of bare sand (regardless of patch size) (Hirst and Attrill, 2008), Z. marina provides a habitat for rare marine species in the UK, such as the Short Snouted Seahorse (Hippocampus hippocampus) and the Spiny/Long Snouted Seahorse (Hippocampus guttulatus). Both seahorse species and their habitat are protected under an amendment to Schedule 5 of the Wildlife and Countryside Act (1981) (Garrick-Maidment et al., 2010). Seagrass also offers a vital nursery habitat for commercial fish species such as cod, pollock, bass (Cullen-Unsworth et al., 2014) and the Common Cuttlefish (Sepia officinalis) that use the beds as preferential spawning sites (Fletcher et al., 2012). Further, seagrass beds dissipate wave action to reduce erosion of coastlines, improve water quality by cycling nutrients, support primary production and provide a food source to wintering wildfowl (Borum et al., 2004; Hemminga and Duarte, 2000). Recognised for their importance, seagrass beds are often designated as protected sites - for example, at an EU level, Z. marina is listed as an Annex 1 habitat under the EU Habitats Directive (EU Commission, 1992). In the UK, they are listed for protection as a Habitat of 
Principal Importance/Priority Habitat, OSPAR List of Threatened and/or Declining Species and Habitats (declining in Region II - North Sea and Region III - Celtic Sea, and threatened in Region V - Wider Atlantic) and as an important feature in estuary Sites of Special Scientific Interest, under the UK Wildlife and Countryside Act 1981 (JNCC, 2015). These legal/policy tools enable the creation of Marine Protected Areas (MPAs) where management can be initiated to protect $Z$. marina from human impacts.

Despite these measures for protection, seagrass beds are one of the most threatened ecosystems globally, declining at a rate of 7\% per year since 1990 (Waycott et al., 2009). Strongholds now remain in limited regions of the UK such as Western Scotland and South West England (Davison and Hughes, 1998), with further densities in North Wales (Egerton, 2011) and on the Eastern Coast of England (Jackson et al., 2016). Although generally a quick growing species (Unsworth et al., 2017), Z. marina has never fully recovered in the UK after a wasting disease devastated the Northern European population in the 1930s (Davison and Hughes, 1998; Hemminga and Duarte, 2000). This lack of recovery is in part due to natural causes such as storms and grazing (Short and Wyllie-Echeverria, 1996); however, it is largely attributed to human disturbances such as coastal development, dredging, agricultural runoff and recreational boating activities (Borum et al., 2004; Hemminga and Duarte, 2000; Jones and Unsworth, 2016).

While not the major cause of seagrass decline, recreational boating in the form of anchoring and swing mooring scour have been found to cause significant damage and to restrict recovery of the habitat (Collins et al., 2010; Liley et al., 2012; Unsworth et al., 2017; Walker et al., 1989). This is due to the shallow, sheltered locations preferred by both recreational vessels and seagrass (Unsworth et al., 2017).

A single anchoring event can influence the physiognomy of an individual plant by pulling up leaves and rhizomes (Ceccherelli et al., 2007; Hastings et al., 1995; Montefalcone et al., 2008; Walker et al., 1989), altering the structure of a meadow

102 (Francour et al., 1999; Montefalcone et al., 2008) during all three stages of an anchor 103 cycle: anchor drop, drag/lock-in and retrieval (Collins et al., 2010; Milazzo et al., 2004). 'Anchor scars' that uproot rhizomes from below the sediment surface have been measured up to $0.16 \mathrm{~m}^{2}$ (Liley et al., 2012), whilst combined anchor and chain impact has caused patches in beds measured between 1-4 $\mathrm{m}^{2}$ (Collins et al., 2010). Predation of the exposed root systems by crustaceans adds further exacerbation (Collins et al., 2010), causing long-term physical disturbance from cumulative anchoring events

109 (Collins et al., 2010; Hastings et al., 1995; Unsworth et al., 2017). Furthermore, 110 traditional swing moorings, inclusive of ground weight, ground chain, riser chain and 111 floating buoy, can scour the underlying seabed when tide and wind movements cause 
112 the chain to swing in a circular motion around the ground weight (Egerton, 2011; 113 Unsworth et al., 2017). Based on a classification of $<10 \%$ seagrass cover, a study by 114 Unsworth et al. (2017) compared swing mooring scars around the UK and discovered 115 that the average scar radius equates to $5.4 \pm 3.5 \mathrm{~m}$, with seagrass thinning a distance 116 of $16-20 \mathrm{~m}$ from the ground weight indicating further influence of the chain. Each swing 117 mooring was measured to cause a seagrass loss of $122 \mathrm{~m}^{2}$, deemed small on a 118 national scale, yet largely significant at a local scale (Unsworth et al., 2017).

119 Globally, eco-mooring designs are being tested in seagrass regions in an 120 attempt to relieve swing mooring damage to seagrass beds, with leading studies 121 currently underway in Australia (Egerton, 2011; Outerbridge, 2013). Designs are 122 variable, featuring either a ground weight or sediment penetrating system and all 123 featuring methods to eradicate chain drag on the seabed using bungees, riser buoys, 124 floating rodes and other creative options (Crown Estate, 2011; Egerton, 2011; Lloyd 125 and Marsland, 2013; Outerbridge, 2013).

126 Previous and current investigations have explored the potential to implement 127 eco-moorings in UK waters (Axelsson et al., 2012; Egerton, 2011). However, due to 128 limited UK-based testing and the differences in tidal range between the UK and 129 Australia, where the majority of trials have taken place, uncertainty as to whether eco130 moorings could be effective in the UK has remained (Egerton, 2011; Outerbridge, 131 2013).

132 It is recognised that public awareness and engagement is crucial to the success 133 of seagrass conservation management (Borum et al., 2004). There are some examples 134 of marine conservation charities attempting to engage the wider public in these issues 135 through citizen science projects, including the Community Seagrass Initiative (CSI) and 136 Project Seagrass, that place education and raising awareness of seagrass at the 137 centre of their work. Initiatives like this provide further evidence that the success of 138 eco-moorings lies not simply in their design, but in their implementation into 139 management (Egerton, 2011) and whether they can receive social acceptance, 140 particularly from recreational boaters, in place of anchoring within seagrass-sensitive 141 sites in UK waters.

142 Despite a growing recognition of seagrass beds as coupled socio-ecological 143 systems (Cullen-Unsworth et al., 2014), there has been a limited number of studies on 144 the publics' perception of seagrass beds or how knowledge has influenced behaviour 145 change. In a study of the UK publics' perceptions of seagrass beds, the results 146 demonstrated that the general public are less enamoured by seagrass as an 147 ecologically important marine plant species (Jefferson et al., 2014). However, other 148 studies have noted that charismatic flagship species such as seahorses can invoke 
149 enthusiasm in conservation campaigns calling for protection of the habitat (Zacharias 150 and Roff, 2001). Despite this, it must be recognised that enthusiasm does not 151 necessarily translate in to action to instigate the necessary management interventions 152 to secure protection of the habitat (Vincent, 2011). It is proposed that to further 153 encourage both individual and community-led behaviour change for environmental 154 protection, a tangible, relatable connection must exist or be made to the species or habitat under threat (Easman et al., 2018; Vincent, 2011).

To truly gauge the success of an eco-mooring trial in Southwest England, this paper examines the physical behavioural responses and perceptions of recreational

158 boaters to understand if a bespoke eco-mooring design (Fig. 1) can reduce anchoring 159 pressure on seagrass beds. Behavioural responses were studied by recording boating 160 activity in 2015 and 2017 within the study site, with an aim to identify and map 161 preferential anchoring areas pre- and post- deployment of the trial eco-mooring to 162 explore behaviour change in a site where no moorings previously existed. 163 Questionnaires were designed to ascertain the demographics of boaters, as well as 164 their seagrass awareness, anchoring/mooring preferences and perceptions of the trial eco-mooring after its deployment in 2017. Given that social engagement is imperative 166 to achieving conservation aims (Jefferson et al., 2015), it was considered crucial that 167 this study collect responses to the deployment of the trial eco-mooring to assess whether future eco-mooring deployments in Torbay could be successful.

\section{Methods and Materials}

\subsection{Case Study Site}

Fishcombe Cove is located west of Brixham harbour in Torbay, Devon (Fig. 2), chosen for deployment of the eco-mooring as it is a popular anchorage site for recreational vessels due to its sheltered location, whilst also providing easy access for monitoring of the eco-mooring (Living Coasts, 2017).

Commercial divers assessed the spatial extent of seagrass in the cove on $25^{\text {th }}$

178 January 2017 , following which a location for the eco-mooring deployment was chosen

$17926 \mathrm{~m}$ east and $23 \mathrm{~m}$ north of the outer extent of the beds, ensuring a distance of $50 \mathrm{~m}$ 180 from the shore. The configuration of the bespoke eco-mooring allows the chain to lift 181 off the seabed using miniature buoys up the riser chain (Fig. 1). The design had undergone prior testing in two coastal and estuarine locations in Kingsand and

183 Salcombe, Devon, UK. One of these eco-moorings had already been in regular use for 184 over two years at the time of this study. The Salcombe eco-mooring had already proven 185 its ecological value in direct comparison with a standard traditional swing mooring, with 
186 seagrass density recorded at over twice as high surrounding the eco-mooring,

187 epifauna demonstrated twice the species richness, and significantly finer sediment

188 composition was found surrounding the eco-mooring ground weight in comparison with

189 the standard swing mooring (Luff et al., In prep). All three results demonstrate the

190 increased levels of disturbance to the seabed from the chain of the traditional swing

191 mooring (Luff et al., In prep).

192 As part of a collaborative effort to improve conservation in the Torbay area, the

193 Torbay Coast and Countryside Trust was initiated in 1999 and within its first operational

194 phase created a Marine Biodiversity Action Plan (Torbay Coast and Countryside Trust,

195 2004). The plan identified seagrass beds as a 'National and Regional Priority Habitat',

196 initiating annual monitoring surveys that mapped and assessed the status of seagrass

197 across many sites in Torbay (Cole, 2016), suggesting restricted anchoring to aid

198 recovery in specific seagrass sites as a result of dive surveys undertaken in 2006 (Flint,

199 2008). In recent years, Torbay has been recognised for its marine biodiversity,

200 designated a candidate Special Area of Conservation (cSAC) under the EU Habitats

201 Directive [92/43/EEC]. The area was also enforced as a Marine Conservation Zone

202 (MCZ) in 2013 (Fig. 2b) as part of the Marine Management Organisation's (MMO)

203 implemented management for the Marine and Coastal Access Act (2009). Although

204 seagrass habitats have been included within all MPA designations for Torbay, their

205 presence has not been the driving factor behind implementation. Rather, recent

206 mitigation has aided some recovery at these sites after a restriction on scallop dredging

207 was introduced in 2014 (Natural England, 2017).

208 Since 2013, coastal management has been conducted by SeaTorbay; a

209 consortium of voluntary partnership organisations that have attempted to address the

210 threats facing Torbay seagrass (SeaTorbay, 2013). Mitigation efforts have included

211 implementation of 'Voluntary No Anchor Zones' (VNAZs) to discourage anchoring in

212 sensitive seagrass sites, whilst also organising the deployment of the trial eco-mooring

213 assessed in this study at Fishcombe Cove. VNAZs cannot entirely prohibit vessel

214 anchoring (Axelsson et al., 2012; Egerton, 2011) in consideration of the public right of

215 navigation ${ }^{\mathrm{a}}$ concerning anchoring in British coastal waters ${ }^{\mathrm{b}}$. They do, however, lessen

216 anchoring activity where voluntary restrictions are generally respected by the majority

217 of the public.

218

\subsection{On-site boating behaviour study}

220 Behavioural responses were studied by observing recreational boating activity

221 with aims to: (1) create and compare anchoring 'hotspots' pre- and post- deployment 
Parry-Wilson et al. Assessing behavioural and social responses to an eco-mooring trial for Zostera marina conservation management in Torbay, Southwest England.

222 of the trial eco-mooring; and (2) calculate anchoring pressure relieved from the

223 seagrass bed by use of the trial eco-mooring during the survey period.

Surveys took place between the $11^{\text {th }}$ June and $7^{\text {th }}$ August 2017 on 19

225 intermittent days to match the temporal commitment of the pre-deployment anchoring

226 study conducted in 2015 between $25^{\text {th }}$ June and $4^{\text {th }}$ August 2015. Mapping of boating

227 activity both in 2015 and 2017 offered direct comparisons of preferential anchoring

228 areas within the study site before and after the deployment of the trial eco-mooring in

229 a site where no mooring previously existed, allowing us to analyse recreational boater

230 behaviour change between the two study years.

231 Boating activity in 2017 was documented manually by using still image 232 photography to observe behaviour for 8 hours a day, whilst questionnaires were 233 undertaken in parallel. In 2015, a fixed camera recorded still images of boating activity 234 continuously at 10 minute intervals during all daylight hours. Every anchoring/mooring 235 event (anchor dropped/retrieved, attached to/detached from eco-mooring) was 236 recorded for use in Geographic Information System (GIS) mapping, whilst 237 observational data such as vessel type (powerboat/sailboat) were recorded in 2017 for use in quantitative and qualitative analysis.

\subsubsection{Desk-based boating activity \& GIS analysis}

Triangulation conducted using Google Earth Pro estimated anchoring coordinates of each vessel both in 2015 and 2017; this was only conducted for vessels located within the boundary of Fishcombe Point where questionnaires could be easily conducted, along a latitude of $50^{\circ} 24^{\prime} 11.67 " \mathrm{~N}$ (Fig. 2c). Co-ordinates were then plotted in ArcGIS 10.5.1 to visualise vessel density. Of 161 anchoring events recorded in 2017, six could not be triangulated due to their hidden position in shallow waters at the southern end of Churston Cove beach (Fig. 2c).

Mapping analysis was conducted in ArcGIS 10.5.1 using point data of anchoring events from both 2015 and 2017 separately. Vessel density maps were created from point data with a linear unit distance of $17.14 \mathrm{~m}$ as an average radius of potential influence to the seabed, calculated from recommendations by the Royal

252 Yachting Association (RYA) (Jinks, 2013). Maps were created separately for both 2015 253 and 2017, then the output layer for 2015 subtracted from the 2017 output layer to 254 calculate variance.

255 Images of seagrass distribution from three volunteer diver transect surveys 256 undertaken in 2017 were provided by the CSI with geotagged coordinates recorded 257 using a Garmin e-trex Global Positioning System (GPS) unit, attached to the surface 
258 marker buoy of each diver. These coordinates were uploaded into ArcGIS 10.5.1 and

259 a polygon created around the exterior data points depicting distributional extent only

260 and not including internal density. Although diver survey data were limited within the

261 scope of this research to allow for a more detailed analysis of seagrass bed spatial

262 fragmentation, seagrass outer spatial extent allowed for direct annual comparison

263 with anchoring distribution and provided the most accurate distributional conditions

264 due to the inter-annual variability of seagrass distribution (Hemminga and Duarte,

265 2000). Time limited additional analysis of seagrass data, where future research could

266 explore annual and perennial variability in seagrass distributions (Phillips et al., 1983)

267 and recovery from anthropogenic impacts.

\subsection{Questionnaires}

Online and on-site questionnaires were developed that contained both

271 qualitative and quantitative question formats to: (1) define socio-demographics of the

272 recreational boating community; (2) ascertain seagrass awareness; (3) understand

273 priorities and anchoring/mooring preferences of boaters in varied circumstances

274 including restricted anchoring sites; and (4) explore social perceptions of the trial eco-

275 mooring. Online and on-site questionnaires included Likert scale, ranked, closed- and

276 open-ended questions. Likert scales between 1 (no confidence at all) to 10 (very

277 confident) were used to gather information on levels of confidence in different mooring

278 types, including the trial eco-mooring. Within the online questionnaire only, ranked

279 scores between 1 (most likely choice) and 9 (least likely choice) identified the preferred

280 actions of boaters when encountering restricted anchoring sites (e.g. VNAZs). Closed-

281 ended questions obtained a variety of data including demographic, anchoring/mooring

282 preferences and knowledge on previous seagrass anchoring actions. Open-ended

283 questions offered respondents opportunities to clarify their responses to closed-ended

284 questions, discuss their knowledge of the eco-mooring trial (on-site) and provide

285 comments on both the questionnaire and wider eco-mooring project. The online and

286 on-site questionnaires differed in length and style of questioning due to the theoretical

287 existence of the trial eco-mooring in the former, and the physical presence of the eco-

288 mooring at the study site in the latter. Both online and on-site questionnaires were

289 developed in collaboration with local stakeholders and piloted on a subset of 290 individuals with an interest in recreational boating. The final format of the questionnaire 291 was approved by the University of Plymouth's ethical committee.

292 On-site questionnaires were conducted face-to-face by stand-up paddleboard 293 between June and August 2017 over 19 intermittent days in parallel with the on-site 294 boating behaviour study, prioritising calm weather in an attempt to ensure visits from 
Parry-Wilson et al. Assessing behavioural and social responses to an eco-mooring trial for Zostera marina conservation management in Torbay, Southwest England.

295 recreational vessels into the cove. Each respondent read a question sheet, inclusive 296 of consent information, with answers recorded on a separate answer sheet by the 297 author to allow the respondent freedom to respond naturally.

298 The online questionnaire was disseminated through an online platform (Survey 299 Monkey) and remained active between $27^{\text {th }}$ May 2017 and $24^{\text {th }}$ July 2017. Three 300 avenues were utilised in an attempt to reach the recreational boating community 301 including word of mouth, email and social media. Emails were sent to senior members of recreational boating groups based between Cornwall and Dorset. Social media enabled respondents from further afield inclusive of non-boating club members to contribute to the study.

\subsubsection{Questionnaire data analysis}

A total of 67 on-site questionnaire responses were collected from the field, with all included in this study. The online questionnaire received 245 responses; respondents indicating that they did not use anchors (dinghy sailors) were removed from final analysis to reduce bias towards moorings, resulting in a sample of 207 complete responses.

Likert responses were analysed using Microsoft excel and reporting the mean score and the standard deviation of the mean. The use of a Likert scale and 'yes/no/unsure' style responses in the closed-ended questions enabled the respondent to provide a positive, negative or uncertain comment to the question. Corresponding open-ended questions then enabled a broader exploration of the themes associated with the individual's response. To reduce subjectivity in data analysis, the NVivo 11 content analysis method was used which facilitated the coding of open-ended comments into a thematic framework to explore rationalisations behind closed-ended answers (see: Rees et al., 2012; Rees et al., 2013).

Data were aggregated further from categories defined in both questionnaires

323 Fishcombe Cove, etc.; available time restricted deeper analysis of these demographics 324 for this study.

325 Ranked scores between nine options in response to the question, 'What would 326 you choose to do (or have previously chosen to do) in response to encountering a site 327 of restricted anchoring in UK waters?', analysed only boater responses that provided 328 scores for all nine options, as it was noted that many respondents provided scores for selected options only.

Statistical exploration of categorical data used non-parametric Kruskal-Wallis tests with Bonferroni adjustment for pairwise comparisons, or Mann Whitney $U$ tests 
Parry-Wilson et al. Assessing behavioural and social responses to an eco-mooring trial for Zostera marina conservation management in Torbay, Southwest England.

332 dependent on number of categories. Likert scale data were tested for normality using

333 the Shapiro-Wilks test and relationships investigated using non-parametric Spearman

334 (rho) product-moment correlation coefficient. IBM SPSS 24 enabled exploration of

335 frequency and statistical analysis of closed-ended nominal, ordinal and scale data.

\section{3. Results}

\subsection{Boating behaviour and seagrass mapping}

Boating activity recorded in 2017 resulted in 161 anchoring events, 32 attachments to the trial eco-mooring and 3 vessels rafting, totalling 196 events with only one day resulting in no vessel activity. This is compared with 127 anchoring events recorded during 2015, with a total of 5 days receiving no activity. Over the 19 survey days in 2017, a decrease in anchoring events occurred that coincided with a decrease in temperatures and increasing wind speeds (Fig. 3).

Of the 196 events documented in 2017, 81.1\% were powerboats with $84.9 \%$ recorded anchoring, $13.2 \%$ attached to the eco-mooring and $1.9 \%$ rafted to another vessel; $44.4 \%$ of those anchoring could have attached to the available eco-mooring upon entry to the cove where one vessel was observed attempting to attach before moving away to drop anchor. The remaining $18.9 \%$ of vessels were sailboats, of which $70.3 \%$ anchored and $29.7 \%$ attached to the eco-mooring; $50 \%$ of those sailboats anchoring could also have attached to the available eco-mooring upon entry to the cove. Of the 196 events, 170 vessels were documented in total where 23 vessels were recorded re-anchoring a maximum of 2 times during a daily visit.

Vessel density maps reveal a difference in cumulative anchoring from a northern spread of vessels in 2015 (Fig. 4a), to a clustered southern density along the inner shore after deployment of the eco-mooring in 2017 (Fig. 4b), with up to 19 fewer vessels in the north of the cove and up to 25 more in the south in 2017 (Fig. 4c).

Of the 161 anchoring events in 2017,36 (22.4\%) were recorded directly within 360 the mapped seagrass outer extent. A further 37 (23\%) anchored within a range of 361 potential influence of the outer extent of the bed (Fig. $4 \mathrm{~d} \& 4 \mathrm{e}$ ), totalling $45.4 \%$ of all anchoring events. Assigning a $45.4 \%$ percentage to the 32 eco-mooring events that have been assumed would have anchored without the eco-mooring available, an additional $20 \%$ (14.5 events) is the estimated percentage of alleviated seagrass anchoring events, either directly within the bed or within the range of potential

366 influence. It must be noted that the mapped outer extent of the seagrass bed does not 367 account for internal fragmentation of the bed; this is suggested as an area of research 368 in need of further attention in relation to anchoring pressure. 
Parry-Wilson et al. Assessing behavioural and social responses to an eco-mooring trial for Zostera marina conservation management in Torbay, Southwest England.

369

370

371

372

373

374

375

376

377

378

379

380

381

382

383

384

385

386

387

388

389

390

391

392

393

394

395

396

397

398

399

400

401

402

403

404

405

\subsection{Recreational boater perceptions}

Of the 170 vessels visiting Fishcombe Cove during survey days, 55.9\% participated in on-site questionnaires (including vessels 'questioned previously'). Of these vessels, $74.6 \%$ were powerboats, and $25.4 \%$ were sailboats. The remaining $44.1 \%$ were not questioned for reasons summarised in Table 1.

\subsubsection{Recreational boating community demographics}

Socio-demographic variables for both online and on-site questionnaires have been summarised in Table 2. Analysis found both online and on-site questionnaires were dominated by $81.6 \%$ and $53.7 \%$ male respondents respectively; $66.9 \%$ of online males were aged $55+$ years, and $57.6 \%$ of on-site males were aged $34-55$ years.

Club membership was noted as a major difference between online and on-site respondents where $88.9 \%$ and $22.4 \%$ confirmed club membership respectively, due to methods of contacting a significant number of sailing clubs for participation online.

The number of on-site respondents decreased with increasing distance from the Torbay coastal region (TQ1-TQ5), with 49.3\% local, 34.3\% regional to Devon county and $16.4 \%$ from other areas around the UK. The remaining $9 \%$ of on-site respondents were identified as not permanently berthed or moored in Torbay from open-ended comments, visiting from Dartmouth, Plymouth (both Devon, UK) and Poole (Dorset, UK).

\subsubsection{Seagrass awareness}

Of on-site respondents questioned, $77.6 \%(n=52)$ were aware of the presence of seagrass around Torbay from various sources such as local knowledge/word of mouth ( $n=20)$, reading signage on the VNAZ buoys $(n=9)$, reading seagrass awareness noticeboards around the coastal paths $(n=6)$ or from water sport activities such as snorkelling, diving and swimming $(n=6)$. A thematic framework detailing where previous knowledge of seagrass presence was gained is shown in Table 3.

Respondents to both online and on-site questionnaires were asked 'Have you ever anchored in a seagrass bed?' and '(If 'yes') Were you aware seagrass was in the area before you anchored?' (see: Figure 5). Of the on-site respondents that advised that they had not previously anchored in seagrass, $72.5 \%$ were recorded anchoring during questioning, of which $27.6 \%$ advised that they visit Fishcombe Cove on average between 15 and 90 days of the year.

\subsubsection{Anchoring and mooring priorities}


Parry-Wilson et al. Assessing behavioural and social responses to an eco-mooring trial for Zostera marina conservation management in Torbay, Southwest England.

Both online and on-site respondents were asked to identify their general preference for the physical actions of either anchoring (dropping the anchor of a vessel) or mooring their vessels (the use of a mooring rope to secure a vessel). Of onsite and online respondents, $74.6 \%$ and $82.8 \%$ respectively confirmed a general preference to moor. Reasons from on-site and online respondents respectively included security (on-site $n=26$; online $n=63$ ), ease of use (on-site $n=24$; online $n$ $=32$ ) and previous anchor problems (on-site $\mathrm{n}=16$; online $n=34$ ), mainly for reasons of anchor drag or drift (on-site $n=14$; online $n=22$ ); e.g. "Provides a secure place to stop without the worry of an anchor dragging". A further 34 respondents anchoring during questioning stated that they prefer to moor rather than anchor, of which $61.8 \%$ had the opportunity to attach to the trial eco-mooring upon entering the cove. Of all anchoring boaters questioned, however, $82.6 \%$ were not aware of the eco-mooring trial. Regarding a preference for moorings, 18 online respondents cited a preference as they assumed this question was inclusive of the option to berth their vessel, highlighting that further clarity in the question could have led to a more accurate response. Anchoring was a preference for $10.5 \%$ on-site and $16.4 \%$ of online respondents, commented by on-site and online respondents respectively as preferential due to flexibility (on-site $n=12$; online $n=19$ ), mainly associated with locations of choice (on-site $n=8$; online $n=14$ ) and independence (on-site $n=6$; online $n=6$ ); e.g. "It allows me more freedom to choose where I want to stay. Adds to the adventure". Online respondents also highlighted the lack of costs associated with anchoring $(n=15)$.

Any respondents answering the questions regarding anchoring in seagrass were compared directly with their preferences for mooring and anchoring. For on-site and online respondents, $31.3 \%$ and $19.3 \%$ of respective respondents who had anchored in seagrass previously indicated their general preference to moor over anchoring (Fig. 6a \& 6b). For individuals aware of the presence of seagrass before they anchored, $36.0 \%$ of on-site and $40.0 \%$ of online respondents also indicated their general preference to moor over anchoring (Fig. 6c \& 6d).

On-site respondents were asked to express an honest opinion to the question 'Do you think VNAZs are necessary around Torbay where seagrass is present?', to which $43.3 \%$ agreed they were, $35.8 \%$ were unsure and $20.9 \%$ did not agree they were necessary, although many commented that they had no awareness of VNAZs around Torbay ( $n=26)$. Open-ended comments to this question were categorised into positive, negative and uncertain responses, based on the responses given to the corresponding closed-ended question, as shown in Table 4. Respondents identified as making positive themed comments towards VNAZs included reasons of seabed conservation 
$443(n=23)$ and that the boaters in question would adhere to them $(n=11)$. Comments 444 identified as uncertain mainly discussed the lack of advertising of VNAZs $(n=24)$ and 445 that alternatives will be required if VNAZs are to be successful $(n=11)$. Negative comments were dominated by two major themes; identifying a want and need to anchor $(n=15)$, and that boaters would be unlikely to adhere to voluntary restrictions

$448 \quad(n=11)$.

449 Online respondents were also asked to rank their mooring or anchoring preferences in the instance that they encounter a restricted anchoring site $(1=$ most 451 likely choice, $9=$ least likely choice). A total of $46.9 \%(n=97)$ respondents provided 452 full rankings for each option, to which mean rankings are visualised in Fig. 7. A further $45319.8 \%$ of all respondents provided only partial rankings for all options given and $33.3 \%$ 454 didn't provide any response to the question.

\subsubsection{Perceptions of the trial eco-mooring design}

Online respondents were shown basic diagrams of a traditional swing mooring and the trial eco-mooring design for comparison, demonstrating a simple mechanism to suspend the riser chain above the seabed (Fig. 1). They were then asked to use a Likert scale to answer the question, "How confident would you feel about using an ecomooring such as the one in the image?' ( $1=$ no confidence at all, $10=$ very confident), shown for comparison with confidence levels in traditional swing mooring reliability in Fig. 8. A mean of 7.27 ( $n=199$, s.d. $= \pm 2.57$ ) was given for the overall confidence of online boaters in the design of the eco-mooring, with scores ranging from 1 to 10 .

The main themes highlighted from respondent uncertainty included questions about the design ( $n=65$ ), mainly apprehensions about adaptations to the riser chain ( $n=45$ ) including the floating chain making contact with vessels $(n=17)$, e.g. "There is a slight challenge that the chain could be floated to the surface and catch my propeller". Positivity towards the eco-mooring stemmed from appreciation of the design ( $n=49$ ) in that it was considered similar to a standard swing configuration ( $n=28)$, or general positivity towards the concept and purpose $(n=22)$, e.g. "No difference between the two as they both do the same thing". Negativity from respondents largely disagreed with variable elements of the design $(n=12)$, such as "The weight of the chain on the sea bed is fundamental to the holding capacity of a mooring". to rate their confidence in the eco-mooring reliability $(1=$ no confidence at all, $10=$ very confident) without being given any indication of the design configuration, to which the overall mean was $8.9(n=43$, s.d. $= \pm 1.32)$ with a range from 5 to 10 (Fig. 8). A statistically significant difference was found between on-site (median $=9.0, n=43$ ) 
480 and online (median $=8.0, n=199)$ scores given for confidence using the eco-mooring $481(U=2577, z=-4.15, p=<0.001, r=-0.27)$.

482 Respondents who had not used the trial eco-mooring on-site were also asked 483 what their reasons were for not attaching to it. The main reasons included lacking 484 awareness of its purpose $(n=26)$, that it was not available for use when they entered 485 the cove $(n=15)$ and that the location of the eco-mooring wasn't ideal $(n=23)$, 486 believed to be too far out from the shore $(n=11)$ and too exposed to environmental conditions $(n=10)$. A previous question asking why boaters visit Fishcombe Cove had identified it as a prime sheltering location from wind and waves $(n=37)$ and local to permanent berthings/moorings within Torbay $(n=16)$. However, $17.9 \%$ of those anchoring had previously attached to the eco-mooring between 1 and 10 times (mean $=2.5$, s.d. $= \pm 2.61$ ) with a median of 1 . Only 1 of these boaters had the opportunity to attach to the trial eco-mooring upon entering the cove, advising that he had chosen not to attach again due to the lack of a fender on the buoy, although he did advise that he had used the eco-mooring previously on 4 occasions.

Overall, $89.6 \%$ of on-site respondents agreed that eco-moorings within the context of the trial design provided free of charge for use, would be a worthwhile addition to seagrass areas around Torbay. Main themes identified for positivity were for seabed conservation $(n=28)$, security and/or safety $(n=16)$ and that the ecomoorings would be actively used by the respondents questioned $(n=14)$. No respondents disagreed with the idea of further eco-moorings of this type around Torbay, although $10.4 \%$ were unsure and expressed uncertainty about the trial ecomooring design $(n=5)$ and potential increased boat traffic in Fishcombe Cove $(n=4)$. mainly positive, agreeing that the eco-mooring trial was a good idea $(n=19)$, that more eco-moorings were needed $(n=14)$ and that increasing awareness for the ecomooring trial, VNAZs and seagrass were all necessary $(n=13)$. Many offered

507 suggestions on how to improve the design of the buoy $(n=9)$, whilst a limited number 508 offered varying negative feedback $(n=8)$.

\section{Discussion}

This study has demonstrated behaviour change in relation to anchoring 512 distributions within the study site when comparing pre- and post- deployment of the eco-mooring in 2015 and 2017 respectively, as well as varied social responses from

514 recreational boaters in response to the online and on-site questionnaires. This 515 discussion will firstly review the changes to boating activity behaviour in relation to 516 seagrass distribution within the study site. Following this, the social perceptions of 
Parry-Wilson et al. Assessing behavioural and social responses to an eco-mooring trial for Zostera marina conservation management in Torbay, Southwest England.

517 recreational boaters will be explored, separating discussions on the varied themes of

518 the online and on-site questionnaires including recreational boating community 519 demographics, seagrass awareness, anchoring and mooring priorities, and 520 perceptions of the trial eco-mooring.

\subsection{Boating behaviour and seagrass mapping}

523 This study recorded a considerably higher number of vessels visiting the study 524 site in 2017 than in 2015 , expected due to the calm weather conditions sought out in 5252017 for on-site questionnaires by paddleboard. Previous studies (Demers et al., 2013; 526 Unsworth et al., 2017) have indicated that both seagrasses and vessels favour 527 locations with reduced water movements and wave action. Within this study, weather 528 was a prime consideration for boaters, who generally chose to visit the cove because 529 of its sheltered nature. Calm, south-westerly winds and air temperatures above $20^{\circ} \mathrm{C}$ 530 led to the three highest daily vessel frequencies in 2017. Increasing wind speeds 531 therefore resulted in a lower attendance of vessels since powerboats are assumed to 532 prioritise calmer conditions than that of sailboats, the latter potentially spending more time 'out sailing' than visiting coves and bays due to the nature of the sport.

A higher percentage of sailboats than powerboats chose to attach to the trial eco-mooring. This could in part be due to a higher awareness of sailors from the environmental education efforts of sailing organisations such as the RYA, although due to the depth of water required for their keel, could equally be for reasons of security considering that the sailboats entering the cove were on average longer in length and therefore assumed heavier than the majority of powerboats recorded. The high percentages of vessels anchoring in the cove when they had the opportunity to attach to the eco-mooring, $44.4 \%$ and $50 \%$ of powerboats and sailboats respectively, suggests that recreational boaters either did not see the eco-mooring upon entry to the cove, chose not to investigate (as large lettering on top highlighted its purpose), or chose to ignore the eco-mooring in favour of preferential anchoring habits.

Although a $17.14 \mathrm{~m}$ radius was applied to each anchoring event to calculate a range of potential influence of the vessel rode on seagrass, strength of influence will undoubtedly decrease away from the anchoring point due to the lift of the chain's catenary curve from the anchor point to the bow of the vessel. However, thinning of seagrass blades has been observed at a $16-20 \mathrm{~m}$ distance from traditional swing moorings caused by the mooring chain (Unsworth et al., 2017). Seagrass thinning is 551 hypothesized to be mirrored by chains of anchoring vessels depending on the length 552 of chain they deploy, if they have a chain or rope rode, and length of visit through 553 changing tides; further study here is suggested. Anchor drag events would also add to 
554 both the spatial range of potential influence and strength of influence within the radii;

555 another area suggested for further research as a large anchor relative to the size of

556 the vessel is likely to create irregular tracks through the seabed and cause greater

557 impacts (Francour et al., 1999). Larger anchors $\sim 12 \mathrm{~kg}$ have potential to damage an

558 average of 34 shoots per anchoring event as measured in a Posidonia oceanica bed

559 (Francour et al., 1999), although this is dependent on anchor style (Milazzo et al., 560 2004).

561 Vessel density maps appear to show an alteration in behaviour of anchoring 562 vessels, shifting their distribution into a more southerly cluster away from the eco563 mooring deployed in 2017. However, this cannot be confirmed without consideration 564 of extraneous factors including weather conditions, as stronger wind conditions in 2017 565 could have persuaded vessels to anchor closer to the shore considering that 566 respondents generally identified that they visit Fishcombe Cove for the shelter it 567 provides. Published RYA advice (Evans, 2011) indicates that the first consideration 568 when choosing any anchorage is "Shelter...ensuring good protection from all wind 569 directions". Vessel safety is therefore likely to have been the prime consideration for recreational boaters, thus creating a natural bias in the answers provided within this

571 study. Shelter was also a priority for $86 \%$ of boaters in another study that specifically 572 chose a seagrass dense area for mooring or anchoring (Lloyd and Marsland, 2013). 573 Nevertheless, the resulting maps could indicate that eco-moorings placed strategically 574 around or even within seagrass beds could alleviate impacts through anchoring vessel 575 displacement whilst providing an alternative mooring system.

$576 \quad$ This study recorded a higher number of anchoring events in 2017 than 2015 577 using comparable methodologies, which is likely to have resulted in a greater level of 578 damage to the seagrass beds in 2017 considering that a single anchoring event alone 579 can be destructive (Ceccherelli et al., 2007; Collins et al., 2010; Francour et al., 1999; 580 Hastings et al., 1995; Montefalcone et al., 2008; Walker et al., 1989). The percentage 581 of anchoring pressure alleviated by the use of the trial eco-mooring, however, is 582 anticipated likely to increase. This is due to the heightened awareness of boaters 583 visiting the study site who were questioned in this study and made aware of the 584 presence of seagrass, in addition to the repeated public use of the trial eco-mooring and anticipated spread of local knowledge regarding its free use.

CSI volunteer diver survey data were used to map the seagrass bed outer extent as opposed to that of a $2016 \mathrm{CSI}$ study, due to the considerable natural annual 588 variability in Z. marina distributions (Hemminga and Duarte, 2000) where beds die back 589 every winter and regrow in the spring (Olesen and Sand-Jensen, 1994; Phillips et al., 590 1983). Using 2017 diver data therefore offered the most recent distributional data to 
Parry-Wilson et al. Assessing behavioural and social responses to an eco-mooring trial for Zostera marina conservation management in Torbay, Southwest England.

591 best estimate the percentage of vessels possibly impacting the bed, as well as the

592 percentage of anchoring damage alleviated through use of the eco-mooring during the

593 study period.

594

\subsection{Recreational boating community demographics}

This study demonstrated that the boating community of Torbay that utilise anchorages around the MCZ are primarily male local or regional powerboat owners without membership to any local or national boating groups, and that could be reached through local harbours, mooring providers or more widely through local businesses including cafes, retailers or public houses. Understandably, seagrass awareness campaigns are currently targeted broadly at the general public unless they are aimed at specific age groups, such as children. Males of the general public have shown stronger utilitarian opinions about wildlife (Miller and McGee, 2000) including marine species in the UK where they demonstrated disinterest in many charismatic flagship species of seagrass conservation campaigns, such as seahorses (Jefferson et al., 2014). Presenting seagrass beds as a practical habitat by clearly defining their various ecosystem services as utilitarian functions, could therefore serve as an opportunistic angle to their portrayal, especially when attempting to educate and incite behaviour change in male powerboat owners identified as the majority of recreational boaters visiting the study site. Targeting education campaigns at specific demographic groups of local recreational boating communities could in turn increase community-driven conservation management and lead to an enhanced sense of marine citizenship (McKinley and Fletcher, 2010), especially where respondents in this study identified a sense of personal attachment to the study site.

The differences in club membership between online and on-site respondents does suggest that further ways of reaching the powerboat community could have been explored for the online questionnaire, since the majority of clubs contacted to participate were sailing-orientated.

\subsection{Seagrass awareness}

A high awareness of seagrass presence was confirmed by on-site respondents from a variety of outlets, mainly indicated as local knowledge. This could be linked to

623 a rise in scientific study and local outreach, since other UK studies have found 624 seagrass to be a recognisable marine plant to the wider general public (Jefferson et 625 al., 2014), even if it is considered to be less charismatic (Duarte et al., 2008). 626 Considering the high number of respondents aware of seagrass presence within the 627 study area, questioning awareness of the threats to seagrass habitats and importance 
628 of ecosystem services they provide could have offered interesting insight to directly 629 compare with boating behaviour during the study. Although seagrass historically has 630 cultural and economic benefits to many worldwide communities, the value of seagrass 631 habitats is not always recognised (Cullen-Unsworth et al., 2014). This has been clearly 632 demonstrated by the removal of seagrass beds in tropical beachside resorts to 633 maintain aesthetics for visiting tourists (Cullen-Unsworth et al., 2014). The 634 development of snorkel safaris and seagrass walks in Wales and Tanzania respectively, however, have shown potential for seagrass eco-tourism as an outreach and educational tool (Cullen-Unsworth et al., 2014; Nordlund et al., 2013).

A higher percentage of on-site respondents compared to online respondents confirmed that they had previously anchored in seagrass, considered understandable since it was identified that the majority remain in the local seagrass-dense waters around the Torbay MCZ. It was, however, surprising to find that boaters recorded anchoring at Fishcombe Cove denied having ever anchored in seagrass, given the number of days that most spent visiting this location annually and the presence of seagrass in this location. It could be reasoned that this proportion of respondents might not be aware of seagrass below them if not hooked on the end of their anchor during retrieval. Alternatively, their response could have been induced by a social desirability bias of respondents who were aware of the conservation aims of the eco-mooring project, found more likely to occur in face-to-face social surveys (Duffy et al., 2005). For those generally aware of seagrass presence, information on the importance of seagrass beds and their locations around the MCZ can be obtained from the many noticeboards around the coastal paths or from Tor Bay Harbour who also include this information on their website (Tor Bay Harbour, 2016b). This signifies that boaters with an awareness of seagrass either lack an understanding of its importance and threats

653 to the habitat, or prioritise their lifestyle choices to visit preferential anchoring sites over 654 consideration for the environment. In order to encourage recreational boaters to 655 prioritise conservation over their lifestyle choices, it has been suggested that positive 656 messages are more successful in stimulating pro-environmental behaviour change 657 over negative ones (Easman et al., 2018; O'Neill et al., 2013). Providing highly visible solutions, such as eco-moorings with positive messages of encouragement for their use, could therefore result in pro-environmental behaviour change within the recreational boating community and a higher public awareness of management strategies that is currently lacking (Easman et al., 2018). 
665 monetary incentive could include charging fees for anchoring vessels in MCZs/VNAZs, 666 funds from which could then contribute towards better enforcement and policing of 667 byelaws in MCZs and aid the deployment and maintenance of further eco-moorings.

668 To ensure successful uptake of monetary incentives such as these, consistency from 669 governance spatially and temporally around the UK would be essential, as adaptations 670 to or removal of incentives would likely be counterproductive (Gneezy et al., 2011).

671 Should free of charge public eco-moorings receive increased use (where none existed previously) and become socially accepted within a community as a mutually 673 beneficial method of mitigating environmental damage, the choice to anchor may 674 decrease as boaters aim to achieve social acceptance against a new 'norm'. If eco675 moorings become commonplace in UK coastal waters, community awareness of their 676 environmental purpose would increase, potentially resulting in image motivated 677 prosocial behaviour changes (Ariely et al., 2009; Gneezy et al., 2011) for those initially 678 less willing to change anchoring behaviours.

\subsection{Anchoring and mooring priorities}

Already demonstrating that the majority of respondents generally prefer the physical action of mooring a vessel to anchoring, direct comparisons with seagrass anchoring responses implies that providing a mooring option in sensitive-seagrass sites around the UK could help alleviate cumulative impacts due to the overall preference to moor. However, the implementation of seagrass friendly eco-moorings is dependent on their social acceptance and widespread adoption (Egerton, 2011). Interestingly, over half of on-site respondents recorded anchoring had the opportunity to attach to the eco-mooring upon entering Fishcombe Cove, although this appears to have been connected to a lack of awareness on its free public use.

On-site respondents gave mixed opinions about the VNAZs in Torbay with over half providing uncertain or negative comments towards them. This may be due to the preference by boaters to continue visiting particular sites around Torbay without any restriction(s). This mirrors the results of research conducted in Studland Bay, Dorset, UK, where previous VNAZs had been implemented, with half of the respondents unwilling to relocate within the bay to avoid anchoring in seagrass (Lloyd and Marsland, 2013). A resistance to behaviour change highlights the need for alternative methods of management and/or mooring to alleviate anchoring and swing mooring damage to the seabed (Lloyd and Marsland, 2013). 
regarding anchoring avoidance in VNAZs. A large number of respondents were not aware of the presence of VNAZs, leading to comments regarding the lack of advertising and recommendations for alternative options to be offered over anchoring.

705 Confusion is understandable given the conflicting advice supplied to boaters.

706 Previously Tor Bay Harbour highlighted Fishcombe Cove as a preferential anchoring 707 site close to Brixham (Tor Bay Harbour, 2016a) whilst also providing conservation 708 information and maps for seagrass beds in the bay (Tor Bay Harbour, 2016b), 709 essentially highlighting a requirement for collaborative national and local governance to provide a clear message through all available channels. It must however be noted

711 that Tor Bay Harbour have now updated their website to reflect the sensitive nature of

712 Fishcombe Cove's seagrass beds as well as the implementation of further eco713 moorings following this study (Tor Bay Harbour, 2018).

714 Ranked boating activity options highlighted that free of charge (FOC) options were a main priority for online boaters, with security of vessels also displaying importance since the top three preferential choices were ranked in order of assumed familiarity; 'berthing $F O C$ ', 'traditional mooring $F O C$ ' and 'eco-mooring $F O C$ ' respectively. There was a distinct separation between the first six options and the latter

719 three; 'raft to another vessel', 'drop anchor' and 'sail to another location' sharing the 720 highest means and lowest rankings (least preferential choices). 'Drop anchor' as a 721 least likely choice is understandable considering the design of the question pertaining 722 to a restricted anchoring site. However, 'sail to another location', as a least likely choice 723 supports other findings that a proportion of boaters are likely to prioritise lifestyle 724 choices such as visiting preferential locations, over relocation for an environmental 725 cause (Lloyd and Marsland, 2013). This question admittedly alluded to VNAZs as an example of restricted anchoring sites, which could have made for a better comparison against on-site responses.

\subsection{Perceptions of the eco-mooring trial}

The contrast in positivity and uncertainty from on-site and online respondents respectively pertaining to confidence in the eco-mooring design, is likely to have stemmed from the visual 'working proof' of the trial eco-mooring in situ for on-site respondents. Online respondents were simply provided with a visual diagram of the

734 basic eco-mooring configuration without evidence of its working use. It is no surprise that design raised much uncertainty in online respondents since a variety of eco-

736 mooring configurations are still being tested worldwide (Egerton, 2011). Similarly, this

737 was a key area of concern for influential stakeholders in an Australian study assessing 738 various eco-mooring trial results (Outerbridge, 2013) where testing is currently more 
739 common than in UK waters. However, on-site respondents expressed a general 740 welcome for the trial eco-mooring in Torbay, scoring their confidence in its reliability 741 significantly higher than online respondents without a visual or verbal description of its 742 configuration. The theory behind retaining imagery or a verbal description from on-site 743 respondents was to test a hypothesis that boaters generally place trust in standard

744 visitor moorings, giving an assumption that all is well beneath the surface of a mooring 745 buoy. This trust from on-site respondents is comprehendible since there is physical 746 evidence of design, planning and deployment efforts on site, influenced by an 747 awareness that the eco-mooring was newly deployed and actively providing a service 748 to visiting boats, whereas online respondents may have assumed the trial design was 749 simply at a conceptual stage. To improve confidence in eco-moorings from the 750 recreational boating community, further evidence and media attention is required on 751 existing eco-mooring trials. Regional projects are gathering this evidence and creating 752 local media interest, especially where recovery of seagrass ecosystems are a result of 753 eco-mooring deployment (Luff et al., In prep), yet these projects are still few in number 754 and take time to gather sufficient evidence from. National media coverage of local 755 success stories like these is paramount in changing public perceptions, where 756 seagrass currently receives the least media attention globally when compared with 757 other coastal habitats including saltmarsh, coral reefs and mangroves (Duarte et al., 758 2008). Raising the profile of seagrass beds as critically important habitats, both for the 759 ecosystem services they provide as well as for the natural biodiversity they support, is 760 crucial to further public understanding of how ecologically and economically important 761 seagrass beds are locally to the UK, as well as globally.

762 On-site respondents largely agreeing with the deployment of further eco763 moorings around Torbay gives a strong indication of the success of this trial at 764 Fishcombe Cove. It was encouraging to find that most recreational boaters cited 765 seabed preservation as the main reason for extension of the eco-mooring project. 766 Security of vessels was a second priority that would undoubtedly benefit the majority 767 of boaters in both the on-site and online questionnaires who indicated a preference for 768 mooring where security was a main theme of rationalisation. General comments from 769 on-site respondents again presented the argument that further eco-moorings, 770 awareness and conservation information would be beneficial to the recreational 771 boating community in sensitive seagrass areas.

\section{Conclusion}

774 It is well cited that coastal habitat management in the UK is in need of 775 improvement (Jackson et al., 2016; Jones and Unsworth, 2016; Langstone Harbour 
776 Board, 2013; Unsworth et al., 2017), especially where locally important seagrass beds

777 face further degradation due to anchoring activity (Egerton, 2011). However, as

778 indicated by this study, there is an opportunity for eco-mooring deployment to be a

779 mutually beneficial mitigation method. Where national conservation efforts are making

780 slow progress to aid the recovery of seagrass beds in the UK to meet Good

781 Environmental Status, urgent changes in top-down management are recommended to

782 include providing public eco-moorings for the recreational boating community in

783 seabed sensitive sites.

784 This study demonstrated that knowledge of seagrass importance does not 785 always equal behavioural change, confirmed by nearly half of on-site respondents who 786 anchored their vessels within the study site, already aware of the presence of 787 seagrass. Most recreational boaters, however, revealed a preference for mooring over 788 anchoring. Management should therefore prioritise the implementation of alternative 789 mooring systems, such as eco-moorings in sensitive-seagrass sites. Mapping efforts 790 suggest that deployment of eco-moorings could stimulate vessel displacement, 791 indicating that strategic placement in or on the edges of seagrass beds could offer 792 mutually beneficial mitigation (away from seagrass beds). In this study the prevailing 793 weather may have influenced the choice of anchoring locations within the study site, 794 therefore longer-term studies into boating behaviour at trial sites is recommended to 795 enable the strategic placement of moorings; taking into account possible displacement 796 effects and weather influence.

797 Incentives should also be considered to encourage the use of eco-moorings 798 and discourage anchoring in sensitive sites. These could include complimentary use 799 of public eco-moorings and/or charging fees for anchoring privileges in MCZs/VNAZs; 800 the fees from the latter option could then improve policing of byelaws and monitoring 801 in MCZs/VNAZs, as well as fund the deployment and maintenance of further eco802 moorings. Deploying further free of charge eco-moorings nationally would inevitably 803 increase their social acceptance and public understanding of their environmental 804 purpose, likely altering long-term behaviour change through the pursuit of social 805 acceptance in those initially less willing to adapt.

806 Improved collaboration from national and local governance giving clear and 807 concise public messages are essential to avoid confusion between anchoring rights 808 and conservation efforts. An example of conflicting advice previously given by a local 809 harbour authority has been highlighted in this paper, having previously promoted 810 anchoring in seagrass-sensitive sites whilst also providing seagrass conservation 811 information. Clear environmental guidance should be aimed towards the wider general 812 public, inclusive of the male powerboat community aged $35+$ years that were 
Parry-Wilson et al. Assessing behavioural and social responses to an eco-mooring trial for Zostera marina conservation management in Torbay, Southwest England.

813 highlighted in this study as the majority of boaters visiting the study site that were 814 mainly non-boating club members. Local governance should aim to disseminate 815 guidance on the importance of seagrass beds and anchor damage to these individuals 816 through local harbours, mooring providers, vessel retailers and businesses including 817 cafes, retailers or public houses.

818 Although top-down management is recommended as a matter of urgency for 819 UK seagrass conservation, stakeholder engagement at the local community level is required to enhance understanding of new regulations imposed. Engagement with stakeholders using the marine environment is crucial and should be tailored to include

822 individuals who may use particular sites for a variety of activities both commercially 823 and recreationally.

824 Overall, this study has demonstrated that the deployment of a particular design 825 of eco-mooring that has already begun proving its worth through a reduction in 826 anchoring events as well as ecologically (Luff et al., In prep), can be socially accepted 827 when trialled in situ, with strong potential for social acceptance within the wider 828 recreational boating community. With additional measures in place to reduce harmful 829 displacement of anchoring activity, improvements to local knowledge of the presence 830 and need to use the mooring, along with concurrent trials to incentivise behaviour 831 change, eco-moorings should be considered as an option to alleviate traditional swing 832 mooring scour and anchoring damage to seagrass beds in subtidal waters of the UK.

\section{Declarations of interest}

836 None.

\section{Acknowledgements}

840 The authors would like to thank the anonymous peer reviewers whose comments have 841 greatly improved the manuscript.

842 We would also like to acknowledge a number of University of Plymouth staff that gave 843 up their time to help with various stages of this research including Michael Williams, 844 Matt Ashley, Andrew Edwards-Jones, Shaun Lewin and Jill Schwarz.

845 Further thanks go out to those who helped recruit members of the boating community 846 to participate in the online questionnaire and to boating clubs who agreed to share the 847 questionnaire with their members; Victory Class Association, Keyhaven Yacht Club, 848 Southerly Owners Association, Tudor Sailing Club and many more. 
Parry-Wilson et al. Assessing behavioural and social responses to an eco-mooring trial for Zostera marina conservation management in Torbay, Southwest England.

850

\section{Funding}

852 This work was partially funded by the University of Plymouth as part of their MSc

853 Applied Marine Science research project module, with the remainder of funds covered 854 by the lead author.
856

877 Commission for Environmental Cooperation, 2016. North America's Blue Carbon:

878 Assessing Seagrass, Salt Marsh and Mangrove Distribution and Carbon Sinks.

879 Report by Commission for Environmental Cooperation., pp. 54.

880 Crown Estate, 2011. Studland Bay Seagrass Project: Visitor Mooring Viability 881 Appraisal: April 2011. Report by Crown Estate, pp. 58. 
Parry-Wilson et al. Assessing behavioural and social responses to an eco-mooring trial for Zostera marina conservation management in Torbay, Southwest England.

882 Cullen-Unsworth, L.C., Nordlund, L.M., Paddock, J., Baker, S., McKenzie, L.J.,

883 Unsworth, R.K.F., 2014. Seagrass meadows globally as a coupled social-ecological

884 system: Implications for human wellbeing. Marine Pollution Bulletin. 83, 387-397.

885 https://doi.org/10.1016/i.marpolbul.2013.06.001.

886 Davison, D.M., Hughes, D.J., 1998. Zostera biotopes: an overview of dynamics and 887 sensitivity characteristics for conservation management of marine SACs. pp. 95.

888 Demers, M.A., Davis, A.R., Knott, N.A., 2013. A comparison of the impact of 889 'seagrass-friendly' boat mooring systems on Posidonia australis. Marine

890 Environmental Research. 83, 54-62.

891 https://doi.org/10.1016/j.marenvres.2012.10.010.

892 Duarte, C.M., Dennison, W.C., Orth, R.J.W., Carruthers, T.J.B., 2008. The Charisma 893 of Coastal Ecosystems: Addressing the Imbalance. Estuaries and Coasts. 31, 233894 238. https://doi.org/10.1007/s12237-008-9038-7.

895 Duffy, B., Smith, K., Terhanian, G., Bremer, J., 2005. Comparing Data from Online 896 and Face-to-face Surveys. International Journal of Market Research. 47, 615-639.

897 https://doi.org/10.1177/1470785305047006022019/04/07.

898 Easman, E.S., Abernethy, K.E., Godley, B.J., 2018. Assessing public awareness of 899 marine environmental threats and conservation efforts. Marine Policy. 87, 234-240.

900 https://doi.org/10.1016/i.marpol.2017.10.030.

901 Egerton, J., 2011. Management of the seagrass bed at Porth Dinllaen. Initial 902 investigation into the use of alternative mooring systems. Report for Gwynedd 903 Council, pp. 37.

904 EU Commission, 1992. Directive 92/43/EEC. The Habitats Directive. pp. 44.

905 Evans, J., 2011. RYA Yacht Sailing Techniques. Royal Yachting Association.

906 Fletcher, S., Rees, S., Gall, S., Jackson, E., Friedrich, L., Rodwell, L., 2012. Securing 907 the benefits of the Marine Conservation Zone Network. A report to The Wildlife Trusts 908 by the Centre for Marine and Coastal Policy Research, Plymouth University, pp. 105.

909 Flint, D., 2008. Torbay Seagrass Bed Monitoring Surveys 2008. Report for Torbay

910 Coast and Countryside Trust, pp. 45.

911 Francour, P., Ganteaume, A., Poulain, M., 1999. Effects of boat anchoring in

912 Posidonia oceanica seagrass beds in the Port-Cros National Park (north-western

913 Mediterranean Sea). Aquatic Conservation: Marine and Freshwater Ecosystems. 9, $914 \quad 391-400$. 
Parry-Wilson et al. Assessing behavioural and social responses to an eco-mooring trial for Zostera marina conservation management in Torbay, Southwest England.

915 Garrick-Maidment, N., Trewhella, S., Hatcher, J., Collins, K.J., Mallinson, J.J., 2010.

916 Seahorse Tagging Project, Studland Bay, Dorset, UK. Marine Biodiversity Records.

917 3, e73. https://doi.org/10.1017/S175526721000062X.

918 Gneezy, U., Meier, S., Rey-Biel, P., 2011. When and Why Incentives (Don't) Work to

919 Modify Behavior. Journal of Economic Perspectives. 25, 191-210.

920 https://doi.org/10.1257/jep.25.4.191.

921 Hastings, K., Hesp, P., Kendrick, G.A., 1995. Seagrass loss associated with boat

922 moorings at Rottnest Island, Western Australia. Ocean \& Coastal Management. 26,

923 225-246. https://doi.org/10.1016/0964-5691(95)00012-Q.

924 Hemminga, M.A., Duarte, C.M., 2000. Seagrass ecology. Cambridge University

925 Press, London, UK.

926 Hirst, J.A., Attrill, M.J., 2008. Small is beautiful: An inverted view of habitat

927 fragmentation in seagrass beds. Estuarine, Coastal and Shelf Science. 78, 811-818.

928 https://doi.org/10.1016/j.ecss.2008.02.020.

929 Jackson, E., Bridger, D., Nancollas, S., Sheehan, E., 2016. Conservation inaction in

930 action for Essex seagrass meadows? Regional Studies in Marine Science. 8, 141 -

931 150. https://doi.org/10.1016/..rsma.2016.10.003.

932 Jackson, E., Griffiths, C.A., Durkin, O., 2013. A guide to assessing and managing

933 anthropogenic impact on marine angiosperm habitat - Part 1: Literature review.

934 Natural England Commissioned Report NECR111, pp. 128.

935 Jefferson, R.L., Bailey, I., Laffoley, D.d.A., Richards, J.P., Attrill, M.J., 2014. Public

936 perceptions of the UK marine environment. Marine Policy. 43, 327-337.

937 https://doi.org/10.1016/i.marpol.2013.07.004.

938 Jefferson, R.L., McKinley, E., Capstick, S., Fletcher, S., Griffin, H., Milanese, M.,

939 2015. Understanding audiences: Making public perceptions research matter to

940 marine conservation. Ocean \& Coastal Management. 115, 61-70.

941 https://doi.org/10.1016/j.ocecoaman.2015.06.014.

942 Jinks, S., 2013. Anchoring; The gear. Available at: http://www.rya.org.uk/knowledge-

943 advice/cruising-tips/hints-tips/Pages/anchoring-the-gear.aspx (Last accessed

$944 \quad 26.08 .2017)$.

945 JNCC, 2015. Seagrass Beds. Available at: http://jncc.defra.gov.uk/page-5540 (Last

946 accessed 17.06.2019). 
Parry-Wilson et al. Assessing behavioural and social responses to an eco-mooring trial for Zostera marina conservation management in Torbay, Southwest England.

947 Jones, B.L., Unsworth, R.K.F., 2016. The perilous state of seagrass in the British

948 Isles. Royal Society Open Science. 3, 150596. https://doi.org/10.1098/rsos.150596.

949 Langstone Harbour Board, 2013. 4: Environment. Annual Report 2013 by Langstone

950 Harbour Board, pp. 25.

951 Liley, D., Morris, R.K.A., Cruickshanks, K., MacLeod, C., Underhill-Day, J., Brereton, 952 T., Mitchell, J., 2012. Identifying best practice in management of activities on Marine

953 Protected Areas. Natural England Commissioned Report NECR108, pp. 155.

954 Living Coasts, 2017. Fishcombe Eco-mooring Q \& A. Available at:

955 https://www.livingcoasts.org.uk/conservation/conservation-campaigns/fishcombe-

956 eco-mooring (Last accessed 06.09.2017).

957 Lloyd, D., Marsland, L., 2013. Studland Seagrass Project Report. A Report for Dorset 958 Wildlife Trust, pp. 15.

959 Luff, A., Sheehan, E., Parry, M., Higgs, N., In prep. A simple modification reduces 960 mooring impacts on seagrass beds. (In preparation).

961 Marine Coastal Access Act, 2009. Pt. 5 Nature Conservation; Ch. 1 Marine

962 Conservation Zones. Act, M.C.A., pp. 347.

963 McKinley, E., Fletcher, S., 2010. Individual responsibility for the oceans? An 964 evaluation of marine citizenship by UK marine practitioners. Ocean \& Coastal 965 Management. 53, 379-384. https://doi.org/10.1016/j.ocecoaman.2010.04.012.

966 Milazzo, M., Badalamenti, F., Ceccherelli, G., Chemello, R., 2004. Boat anchoring on 967 Posidonia oceanica beds in a marine protected area (Italy, western Mediterranean):

968 Effect of anchor types in different anchoring stages. Journal of Experimental Marine 969 Biology and Ecology. 299, 51-62. https://doi.org/10.1016/i.jembe.2003.09.003.

970 Miller, K.K., McGee, T.K., 2000. Sex differences in values and knowledge of wildlife 971 in Victoria, Australia. Human Dimensions of Wildlife. 5, 54-68.

972 https://doi.org/10.1080/10871200009359179.

973 Montefalcone, M., Chiantore, M., Lanzone, A., Morri, C., Albertelli, G., Bianchi, C.N., 974 2008. BACI design reveals the decline of the seagrass Posidonia oceanica induced 975 by anchoring. Marine Pollution Bulletin. 56, 1637-1645.

976 https://doi.org/10.1016/j.marpolbul.2008.05.013.

977 Natural England, 2017. Torbay Marine Conservation Zone: DRAFT Supplementary 978 advice on conserving and restoring site features, pp. 62. 
Parry-Wilson et al. Assessing behavioural and social responses to an eco-mooring trial for Zostera marina conservation management in Torbay, Southwest England.

979 Nordlund, L.M., Kloiber, U., Carter, E., Riedmiller, S., 2013. Chumbe Island Coral

980 Park—governance analysis. Marine Policy. 41, 110-117.

981 https://doi.org/10.1016/j.marpol.2012.12.018.

982 O'Neill, S.J., Boykoff, M., Niemeyer, S., Day, S.A., 2013. On the use of imagery for 983 climate change engagement. Global Environmental Change. 23, 413-421.

984 https://doi.org/10.1016/i.gloenvcha.2012.11.006.

985 Olesen, B., Sand-Jensen, K., 1994. Biomass-density patterns in the temperate

986 seagrass Zostera marina. Marine Ecology Progress Series. 109, 283-291.

987 https://doi.org/10.3354/meps109283.

988 Outerbridge, N., 2013. An evaluation of recent trials on "environmentally friendly"

989 moorings (EFMs), to inform the development of policy in New South Wales (NSW).

990 Undergraduate Thesis, Southern Cross University, Australia, pp. 53.

991 Phillips, R.C., Grant, S.W., McRoy, P.C., 1983. Reproductive strategies of eelgrass

992 (Zostera marina L.). Aquatic Botany. 16, 1-20. https://doi.org/10.1016/0304-

$993 \quad \underline{3770(83) 90047-5 .}$.

994 Rees, S., Attrill, M.J., Austen, M., Mangi, S., Rodwell, L., 2012. A thematic cost-

995 benefit analysis of a marine protected area. Journal of environmental management.

996 114, 476-485. https://doi.org/10.1016/i.jenvman.2012.10.048.

997 Rees, S.E., Rodwell, L.D., Searle, S., Bell, A., 2013. Identifying the issues and

998 options for managing the social impacts of Marine Protected Areas on a small fishing 999 community. Fisheries Research. 146, 51-58.

1000 https://doi.org/10.1016/j.fishres.2013.04.003.

1001 SeaTorbay, 2013. Torbay Coastal Zone Management Plan 2013-2018, p. 39.

1002 Short, F.T., Wyllie-Echeverria, S., 1996. Natural and human-induced disturbance of 1003 seagrasses. Environmental Conservation. 23, 17-27.

1004 https://doi.org/10.1017/S0376892900038212.

1005 Tor Bay Harbour, 2016a. Leisure: Visiting Craft. Available at: http://www.tor-bay-

1006 harbour.co.uk/harbours/leisure/visitingcraft.htm (Last accessed 06.09.2017).

1007 Tor Bay Harbour, 2016b. Seagrass. Available at: http://www.tor-bay-

1008 harbour.co.uk/harbours/environmental/seagrass.htm (Last accessed 11.09.2017).

1009 Tor Bay Harbour, 2018. Visitors. Available at: http://www.tor-bay-

1010 harbour.co.uk/visitors/ (Last accessed 29.10.2018). 
Parry-Wilson et al. Assessing behavioural and social responses to an eco-mooring trial for Zostera marina conservation management in Torbay, Southwest England.

1011 Torbay Coast and Countryside Trust, 2004. Habitat and species action plans. Torbay

1012 Marine Biodiversity Action Plan 2004-2012. Torbay Coast and Countryside Trust, UK,

1013 pp. 10-11.

1014 Unsworth, R.K.F., Williams, B., Jones, B.L., Cullen-Unsworth, L.C., 2017. Rocking

1015 the Boat: Damage to Eelgrass by Swinging Boat Moorings. Frontiers in Plant

1016 Science. 8, 1309. https://doi.org/10.3389/fpls.2017.01309.

1017 Vincent, A.C.J., 2011. Saving the shallows: focusing marine conservation where

1018 people might care. Aquatic Conservation: Marine and Freshwater Ecosystems. 21,

1019 495-499. https://doi.org/10.1002/aqc.1226.

1020 Walker, D.I., Lukatelich, R.J., Bastyan, G., McComb, A.J., 1989. Effect of boat

1021 moorings on seagrass beds near Perth, Western Australia. Aquatic Botany. 36, 69-

1022 77. https://doi.org/10.1016/0304-3770(89)90092-2.

1023 Waycott, M., Duarte, C.M., Carruthers, T.J.B., Orth, R.J., Dennison, W.C., Olyarnik,

1024 S., Calladine, A., Fourqurean, J.W., Heck, K.L., Hughes, A.R., Kendrick, G.A.,

1025 Kenworthy, W.J., Short, F.T., Williams, S.L., 2009. Accelerating loss of seagrasses

1026 across the globe threatens coastal ecosystems. Proceedings of the National

1027 Academy of Sciences USA. 106, 12377-12381.

1028 https://doi.org/10.1073/pnas.0905620106.

1029 Wildlife and Countryside Act, 1981. Pt. 1 Widlife; Ch. 69; Sch. 5 Animals which are 1030 protected, pp. 130.

1031 World Weather Online, 2017. Torquay, Devon Historical Weather. Available at:

1032 https://www.worldweatheronline.com/torquay-weather-history/devon/gb.aspx (Last

1033 accessed 31.08.2017).

1034 Zacharias, M.A., Roff, J.C., 2001. Use of focal species in marine conservation and

1035 management: a review and critique. Aquatic Conservation: Marine and Freshwater

1036 Ecosystems. 11, 59-76. https://doi.org/10.1002/aqc.429.

1037

1038

1039

1040

1041

1042

1043

(C) 2019. This manuscript version is made 


\section{Figures}

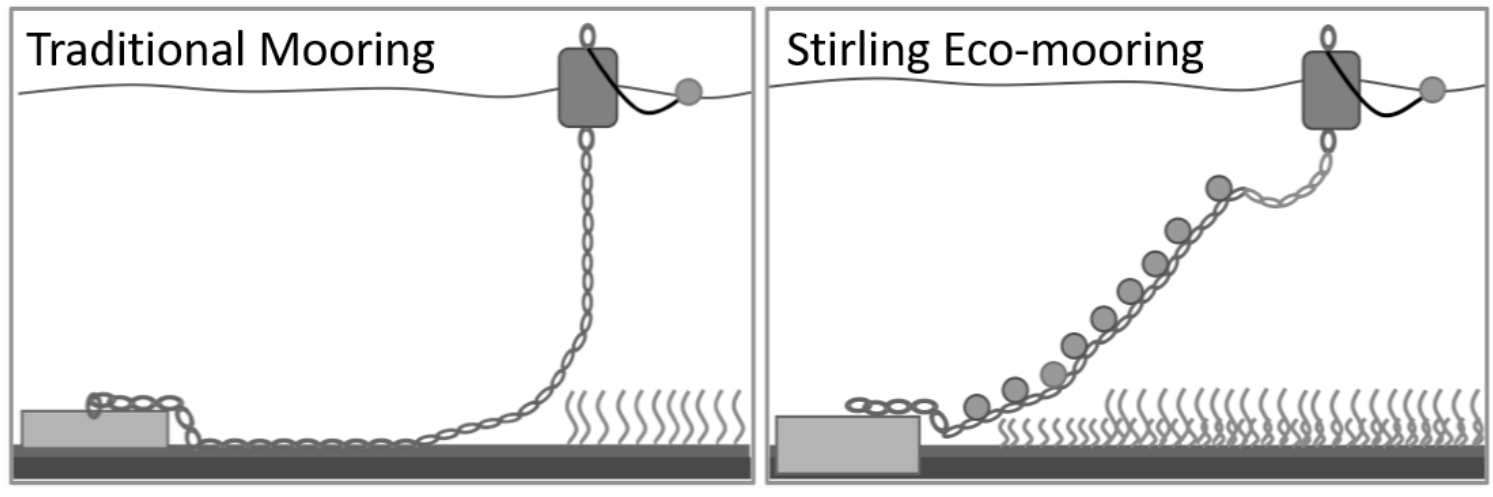

Fig. 1: Diagram of traditional versus bespoke Stirling eco-mooring

Diagram depicting the differences between a) a general traditional swing mooring and b) the National Marine Aquarium's Stirling Eco-mooring with double the tonnage of a standard ground weight and buoys along the riser chain. Image adapted from that kindly provided by the National Marine Aquarium. 


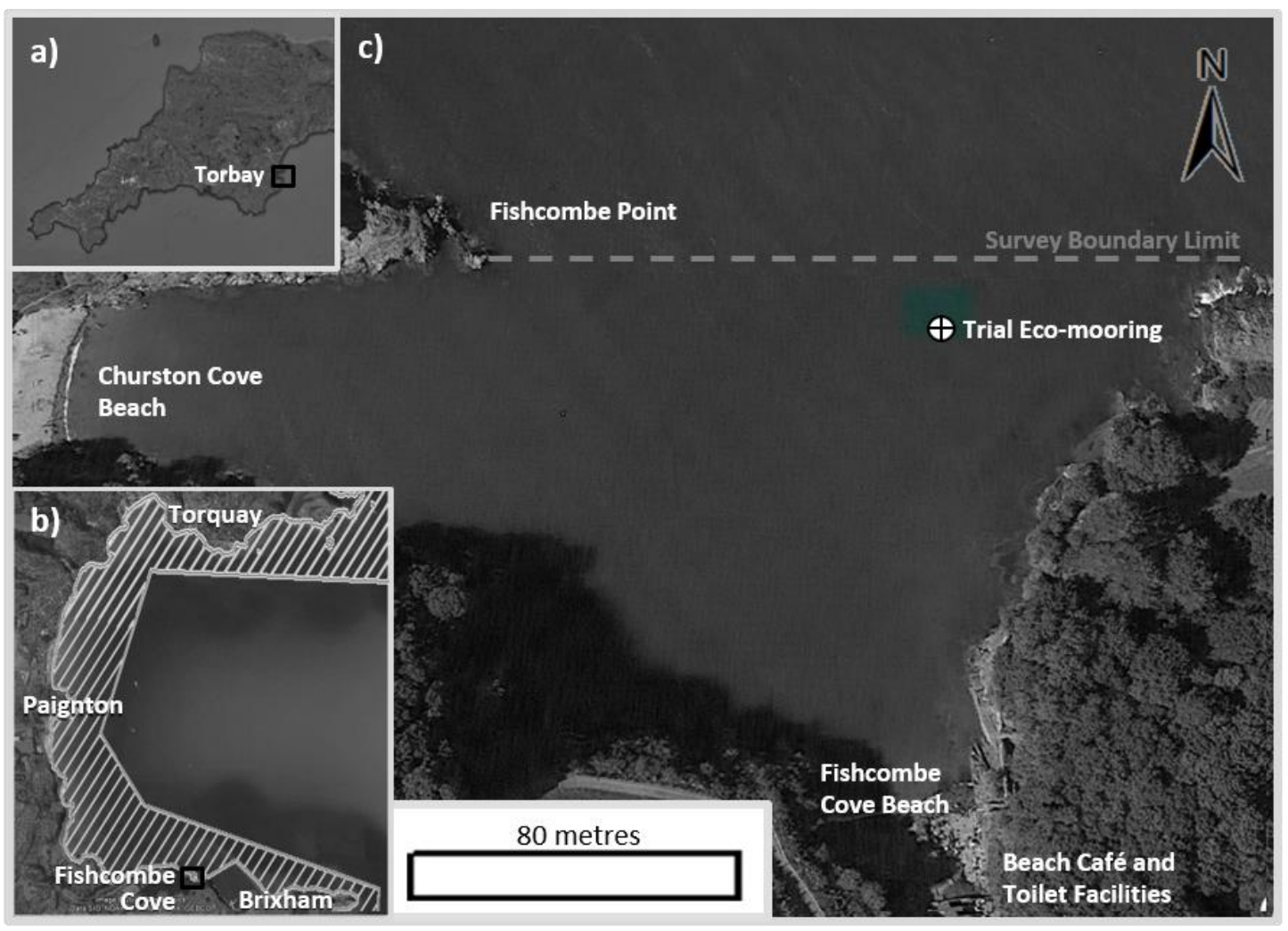

Fig. 2: Map of study site and eco-mooring location

Location of study site in relation to (a) Southwest England (Devon and Cornwall) region and (b) Torbay region showing a section of the designated MCZ (hatched polygon). Figure (c) shows localised study site of Fishcombe Cove including polygons where location of trial eco-mooring identified with a $\bigoplus$ symbol. Devon and Cornwall, Torbay and Fishcombe Cove satellite images from Landsat/Copernicus satellites obtained from Google Earth Pro. Polygon mapping layer of Torbay MCZ from Natural England, accessed via MAGIC online mapping software. 


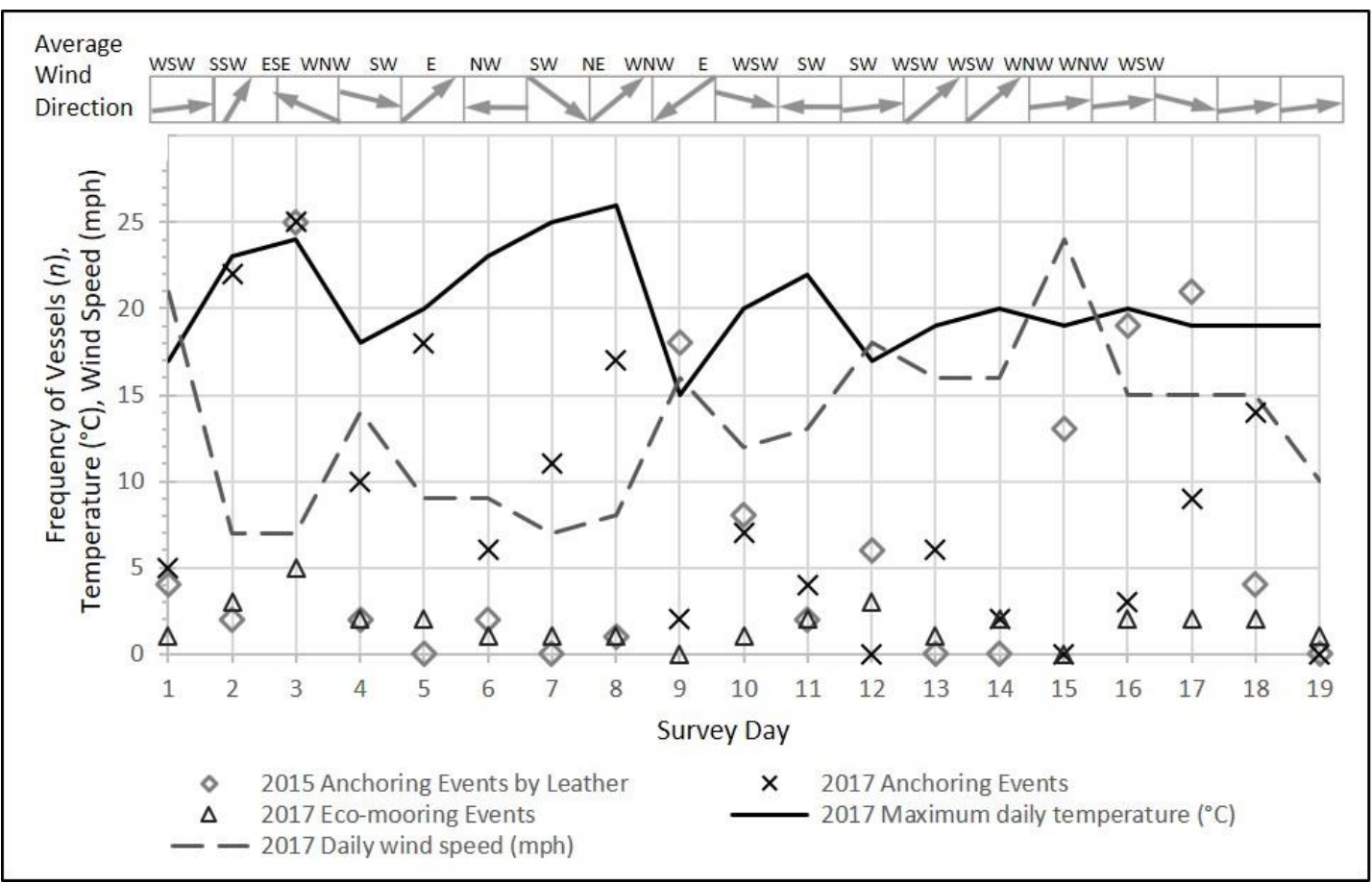

Fig. 3: Vessel frequency and weather comparison

Scatterplot of vessel frequency presenting anchoring events (black crosses) and eco-mooring attachments (black triangles) in 2017, compared with anchoring events recorded in 2015 (grey diamonds). Weather elements including maximum air temperature $\left({ }^{\circ} \mathrm{C}\right.$; black line), maximum wind speed (mph; grey dashed line) and average daily wind direction for 2017 survey days have been added for additional comparison, provided by World Weather Online (2017). 

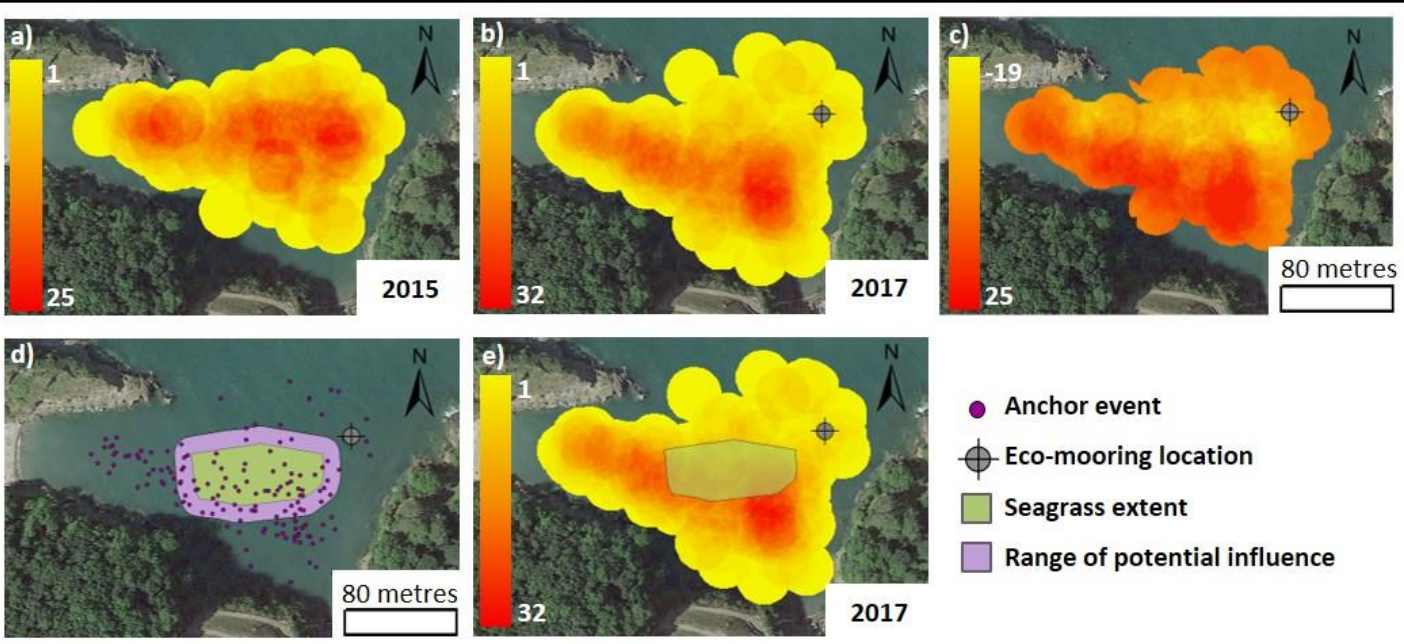

\section{Fig. 4: Vessel density and seagrass extent maps}

Maps of Fishcombe Cove study site shown using point data for anchoring locations and $17.14 \mathrm{~m}$ radius of potential influence on the seabed, indicated with colour bars for pre (2015) and post (2017) installation of the trial eco-mooring including: a) vessel density of 127 anchoring events over 19 days in 2015; b) vessel density of 161 anchoring events over 19 days in 2017; c) anchoring density variance where positive and negative integers represent variance when the 2015 layer is subtracted from the 2017 layer (mean $=1.22$, s.d. $= \pm 8.12$ ); d) 2017 anchor events mapped against 2017 seagrass distribution polygon created from data provided by Community Seagrass Initiative with a $17.14 \mathrm{~m}$ zone of potential influence where vessels anchored can affect the outer edge of the seagrass bed; and e) location of trial eco-mooring and 2017 vessel density in relation to 2017 seagrass extent. Basemaps taken from Google Earth Pro, created in ArcGIS 10.5.1. 


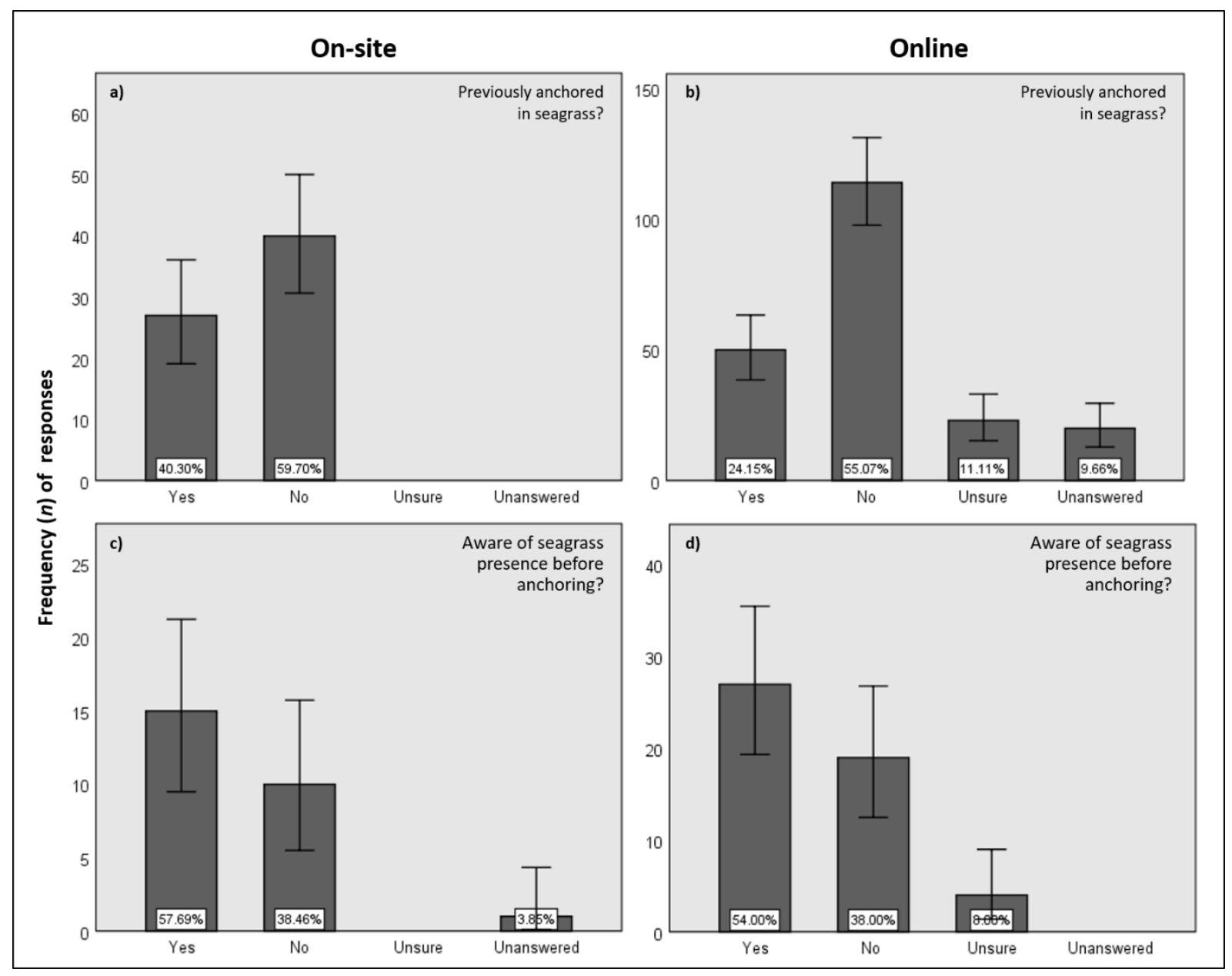

Fig. 5: Recreational boater seagrass awareness

Bar chart showing frequency and percentage of questionnaire responses to the questions (a \& b) "Have you ever anchored in a seagrass bed?", and for those who had (c \& d) "Were you aware seagrass was in the area before you anchored?'. It should be noted that on-site questionnaires did not offer the option of 'Unsure' for the first question (a). Online questionnaires also did not offer respondents the option to provide no response for the second question (d) if they had responded 'Yes' to the first question (b), therefore leaving it impossible to result in any "Unanswered" responses. Error bars show confidence interval at $95 \%$ level. 


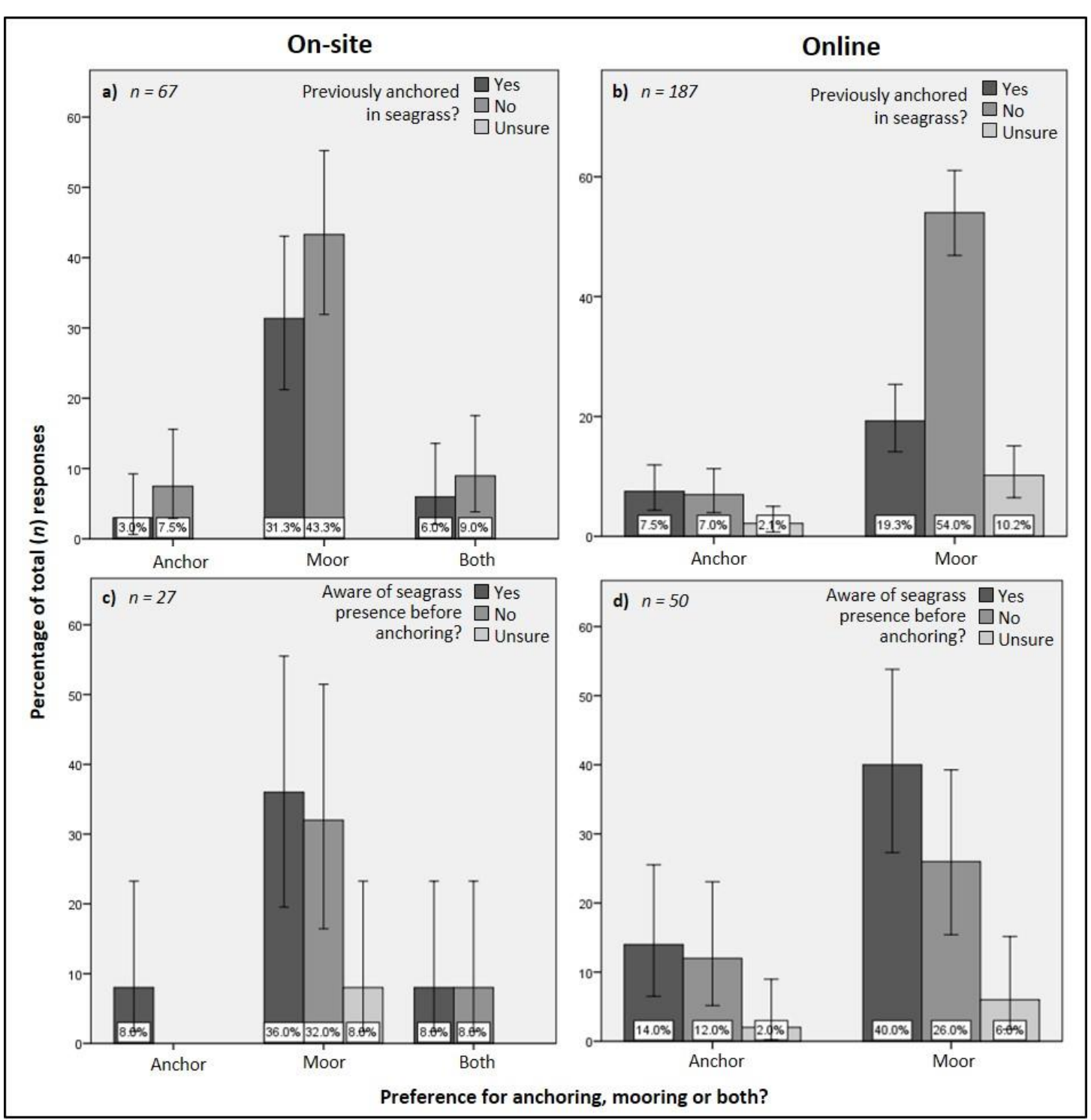

Fig. 6: Seagrass awareness against mooring preferences

Clustered bar chart showing respondent preferences for anchoring, mooring or both, separated into percentages categorised by their answers to the question ( $a$ \& b) "Have you ever anchored in a seagrass bed?', and for those who had (c \& d) "Were you aware seagrass was in the area before you anchored?”. Error bars show confidence interval at $95 \%$ level. 
Parry-Wilson et al. Assessing behavioural and social responses to an eco-mooring trial for Zostera marina conservation management in Torbay, Southwest England.

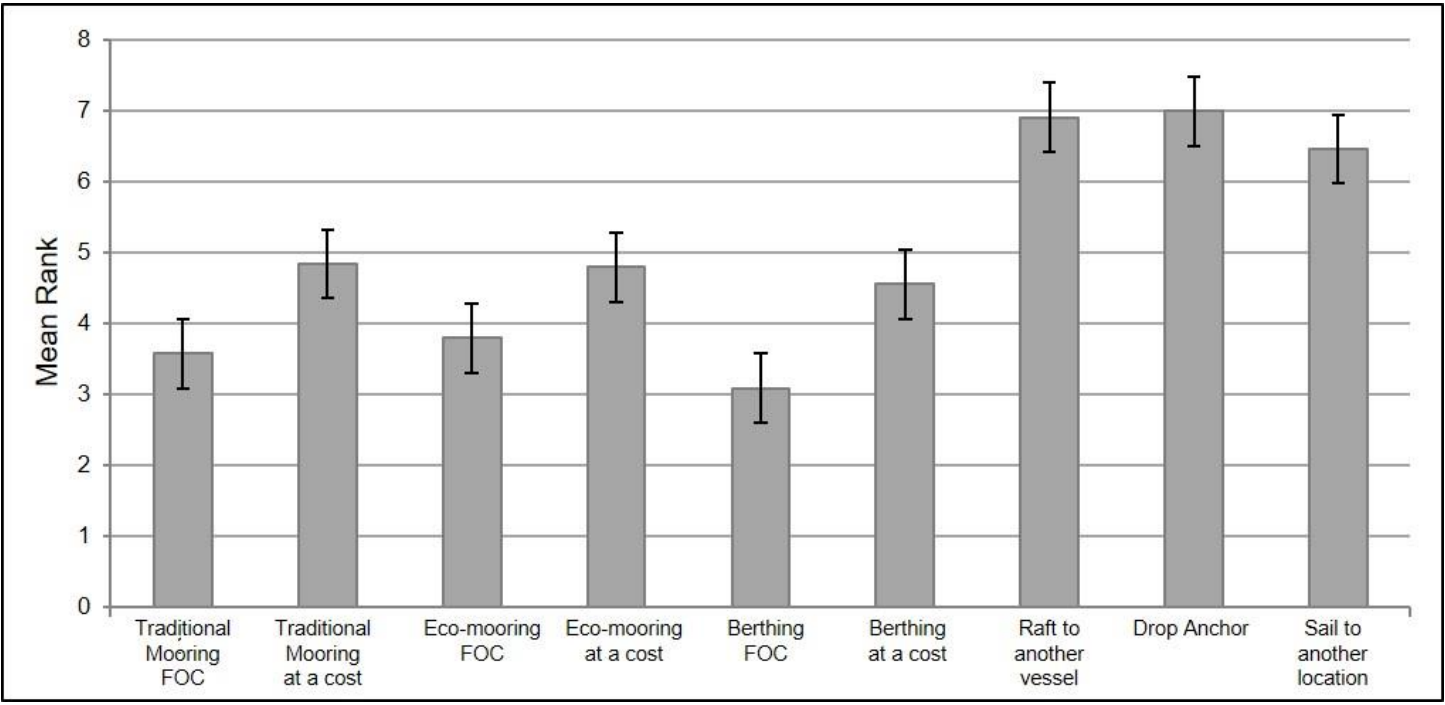

Fig. 7: Results from online respondents ranking preferential options

Bar chart presenting means and standard errors for options ranked from 1 (most likely choice) to 9 (least likely choice) to the question, "What would you choose to do (or have previously chosen to do) in response to encountering a site of restricted anchoring in UK waters?", asked to online respondents $(n=95)$. Note that lower means and therefore smaller bars represent the most likely choices. FOC $=$ free of charge. 
Parry-Wilson et al. Assessing behavioural and social responses to an eco-mooring trial for Zostera marina conservation management in Torbay, Southwest England.

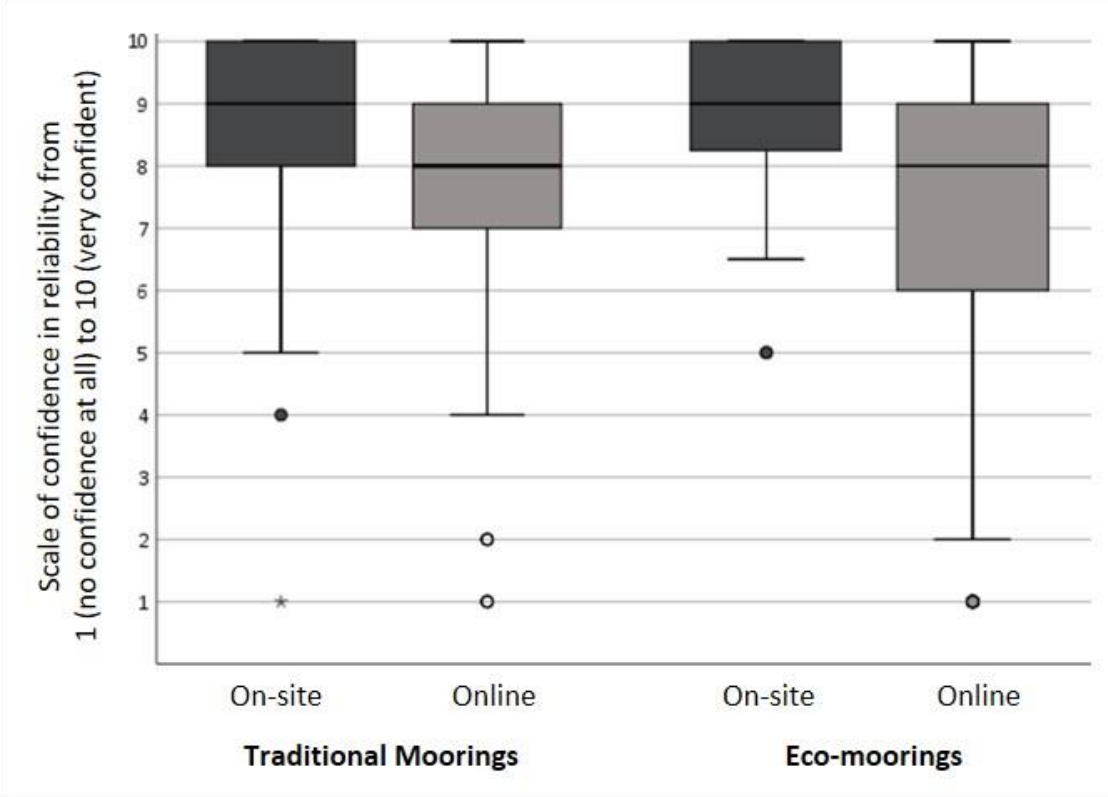

1162

Fig. 8: Confidence levels in traditional and eco-moorings

Box plots displaying scale of confidence in reliability of traditional swing moorings versus eco-moorings from both on-site (dark grey box plots) and online (lighter grey box plots) respondents. Boxes show interquartile range, thick black lines indicate median, t-bars show range, circles indicate outliers and asterisk indicates extreme outlier from the data.

\section{3}


Parry-Wilson et al. Assessing behavioural and social responses to an eco-mooring trial for Zostera marina conservation management in Torbay, Southwest England.

\section{Tables}

1182

\section{Table 1: On-site questionnaire participation}

This table shows the varying participation of recreational boaters to the on-site questionnaires from those recorded visiting the study site over 19 days between the hours of 09:30-17:30. The 'On-site vessel participation' column defines categories within which all visiting vessels recorded during the boating activity study have been sorted. The 'Total vessel frequency' column percentages are representative of the total number of vessels over the course of the surveying period of 19 days (e.g. $n=170)$. Anchoring, mooring and rafting vessel frequency percentages add up to their respective 'Total vessel frequencies' in bold.

\begin{tabular}{|c|c|c|c|c|}
\hline $\begin{array}{l}\text { On-site vessel } \\
\text { participation }\end{array}$ & $\begin{array}{l}\text { Total vessel } \\
\text { frequency \% (n) }\end{array}$ & $\begin{array}{l}\text { Anchoring vessel } \\
\text { frequency } \%(n)\end{array}$ & $\begin{array}{l}\text { Mooring vessel } \\
\text { frequency } \%(n)\end{array}$ & $\begin{array}{l}\text { Rafting vessel } \\
\text { frequency } \%(n)\end{array}$ \\
\hline Total Vessels & $100(170)$ & $80.6(137)$ & $17.6(30)$ & $1.8(3)$ \\
\hline $\begin{array}{l}\text { - Successfully } \\
\text { questioned }\end{array}$ & 39.4 (67) & $68.7(46)$ & $29.8(20)$ & $1.5(1)$ \\
\hline - Missed & $34.1(58)$ & 89.7 (52) & $6.9(4)$ & $3.4(2)$ \\
\hline $\begin{array}{c}\text { - Questioned } \\
\text { previously }\end{array}$ & $16.5(28)$ & $85.7(24)$ & $14.3(4)$ & -- \\
\hline $\begin{array}{l}\text { - Refused } \\
\text { participation }\end{array}$ & $3.5(6)$ & $83.3(5)$ & $16.7(1)$ & -- \\
\hline $\begin{array}{l}\text { - Already } \\
\text { completed online } \\
\text { questionnaire }\end{array}$ & $2.9(5)$ & $100(5)$ & -- & -- \\
\hline $\begin{array}{l}\text { - Under } \\
\text { approachable age } \\
\text { (18 years) }\end{array}$ & $2.9(5)$ & $100(5)$ & -- & -- \\
\hline $\begin{array}{c}\text { - Working vessels } \\
\text { not approached }\end{array}$ & $0.7(1)$ & -- & $100(1)$ & -- \\
\hline
\end{tabular}

1183 
Parry-Wilson et al. Assessing behavioural and social responses to an eco-mooring trial for Zostera marina conservation management in Torbay, Southwest England.

\section{Table 2: Demographics of on-site and online respondents}

Breakdown of demographics of both online $(n=207)$ and on-site $(n=67)$ recreational boating respondents after data aggregation. Where $n$ is not equal to the maximum number of respondents questioned, responses were not given for that question and $\mathrm{n}$ is indicated in the demographic variable header. Variations did occur in demographics sought in online and on-site questionnaires separately where data is missing.

\begin{tabular}{|c|c|c|c|c|c|}
\hline $\begin{array}{l}\text { Demographic } \\
\text { Variable }\end{array}$ & $\begin{array}{l}\text { Online } \\
\text { Respondents } \\
\%(n)\end{array}$ & $\begin{array}{l}\text { On-site } \\
\text { Respondents } \\
\%(n)\end{array}$ & $\begin{array}{l}\text { Demographic } \\
\text { Variable }\end{array}$ & $\begin{array}{l}\text { Online } \\
\text { Respondents } \\
\%(n)\end{array}$ & $\begin{array}{l}\text { On-site } \\
\text { Respondents } \\
\%(n)\end{array}$ \\
\hline Gender & $(n=207)$ & $(n=67)$ & Residency & -- & $(n=67)$ \\
\hline - Male & 81.6 (169) & $53.7(36)$ & $\begin{array}{l}\text { - Local: (TQ1- } \\
\text { TQ5) }\end{array}$ & -- & $49.3(33)$ \\
\hline - Female & $18.4(38)$ & $7.5(5)$ & $\begin{array}{l}\text { - Regional: } \\
\text { Devon }\end{array}$ & -- & $34.3(23)$ \\
\hline - Couple & -- & $38.8(26)$ & $\begin{array}{l}\text { - National: Rest } \\
\text { of UK }\end{array}$ & -- & $16.4(11)$ \\
\hline Age Group & $(n=207)$ & $(n=67)$ & $\begin{array}{l}\text { Average no. } \\
\text { days sailing UK } \\
\text { coast }\end{array}$ & $(n=207)$ & $(n=67)$ \\
\hline - 18-34 years & $5.8(12)$ & $13.5(9)$ & - Low: $1-30$ days & $41.1(85)$ & $47.8(32)$ \\
\hline - 45-54 years & $32.8(68)$ & $49.2(33)$ & $\begin{array}{l}\text { - Mid: 31-90 } \\
\text { days }\end{array}$ & $41.1(85)$ & $37.3(25)$ \\
\hline$-55+$ years & $61.3(127)$ & $22.4(15)$ & - High: > 91 days & $17.8(37)$ & $14.9(10)$ \\
\hline $\begin{array}{l}\text { Member of a } \\
\text { Boating } \\
\text { Club/Group }\end{array}$ & $(n=207)$ & $(n=67)$ & $\begin{array}{l}\text { Average no. } \\
\text { days visiting FC } \\
\text { by sea }\end{array}$ & -- & $(n=67)$ \\
\hline - Yes & $88.9(184)$ & $22.4(15)$ & - Low: 1-14 days & -- & $67.2(45)$ \\
\hline $\begin{array}{l}\text { - No/No } \\
\text { response }\end{array}$ & $11.1(23)$ & $77.6(52)$ & $\begin{array}{l}\text { - Mid: } 15-30 \\
\text { days }\end{array}$ & -- & $19.4(13)$ \\
\hline Vessel Type & -- & $(n=67)$ & - High: $31+$ days & -- & 13.4 (9) \\
\hline - Power & -- & $76.1(51)$ & $\begin{array}{l}\text { Average no. } \\
\text { days anchoring } \\
\text { in Torbay }\end{array}$ & -- & $(n=65)$ \\
\hline - Sailboat & -- & $23.9(16)$ & - Low: 1-14 days & -- & $46.2(30)$ \\
\hline Value of Vessel & $(n=199)$ & & $\begin{array}{l}\text { - Mid: } 15-30 \\
\text { days }\end{array}$ & -- & $26.1(17)$ \\
\hline - <£24,999 & $59.4(118)$ & -- & & & \\
\hline $\begin{array}{l}-£ 25,000- \\
£ 99,999\end{array}$ & $30.6(61)$ & -- & & & \\
\hline$->£ 100,000$ & $10.0(20)$ & -- & & & \\
\hline
\end{tabular}


Parry-Wilson et al. Assessing behavioural and social responses to an eco-mooring trial for Zostera marina conservation management in Torbay, Southwest England.

\section{Table 3: Thematic framework of on-site respondent seagrass awareness}

A thematic framework of open-ended comments from on-site respondents when asked 'Are you aware seagrass is present in Fishcombe Cove and around Torbay and if yes, how were you made aware?'. Frequency of respondents show the number of boaters who provided comments pertaining to each theme and are in descending order from most popular themed comment to least.

\begin{tabular}{ll|ll}
\hline $\begin{array}{l}\text { Themes identifying source of } \\
\text { seagrass awareness }\end{array}$ & $\begin{array}{l}\text { Frequency of } \\
\text { respondents }\end{array}$ & $\begin{array}{l}\text { Themes identifying source of } \\
\text { seagrass awareness }\end{array}$ & $\begin{array}{l}\text { Frequency of } \\
\text { respondents }\end{array}$ \\
\hline $\begin{array}{l}\text { Word of mouth, local knowledge } \\
\text { Read VNAZ buoys }\end{array}$ & 20 & $\begin{array}{l}\text { Received email from marina } \\
\text { Social media } \\
\text { Through knowledge of Studland }\end{array}$ & 2 \\
$\begin{array}{l}\text { Activities undertaken; diving, } \\
\text { snorkelling, } \\
\quad \text { swimming }\end{array}$ & 9 & seagrass & 2 \\
$\begin{array}{l}\text { Read billboards around Torbay } \\
\text { Watched eco-mooring deployment }\end{array}$ & 2 \\
$\begin{array}{l}\text { Read in newspaper or magazine } \\
\text { Informed at local event (Brixfest, } \\
\text { Paignton } \\
\text { Festival, etc) }\end{array}$ & 5 & video & 2 \\
\hline
\end{tabular}


Parry-Wilson et al. Assessing behavioural and social responses to an eco-mooring trial for Zostera marina conservation management in Torbay, Southwest England.

\section{Table 4: Thematic framework of on-site responses to Torbay VNAZs}

A thematic framework of open-ended comments from on-site respondents when asked 'Do you think that 'voluntary no anchor zones' (VNAZs) are necessary in Torbay where seagrass is present?'. Responses are in descending order from most popular themed comment to least. Themed comments entered into the main emotive categories (bold headers) of 'positive', 'negative' and 'uncertain' were validated by the corresponding closed question which identified comments as positive/negative/uncertain based on the framing of the question. Themed comments within each emotive category with higher frequencies are split into parent and child categories (child indicated in italics) where possible, to explore further details pertaining to popular themes.

\begin{tabular}{|c|c|c|c|}
\hline Themed comments on Torbay VNAZs & $\begin{array}{l}\text { Frequency of } \\
\text { respondents }\end{array}$ & Themed comments on Torbay VNAZs & $\begin{array}{l}\text { Frequency } \\
\text { of } \\
\text { respondents }\end{array}$ \\
\hline Uncertain & & Negative & \\
\hline Not adequately advertised & 24 & Anchoring is preferential & 24 \\
\hline Alternatives needed & 11 & - $\quad$ Need and want to anchor & 15 \\
\hline $\begin{array}{l}\text { Need evidence of seagrass importance } \\
\text { and proof of anchor damage }\end{array}$ & 7 & - Boaters won't adhere to VNAZs & 11 \\
\hline VNAZ buoys assumed only 5 knot buoys & 2 & $\begin{array}{l}\text { - Worried about complete anchoring } \\
\text { restrictions }\end{array}$ & 2 \\
\hline $\begin{array}{l}\text { Assumed seagrass surrounds VNAZ } \\
\text { buoys }\end{array}$ & 1 & $\begin{array}{l}\text { Boaters can be respectful of the seabed } \\
\text { without VNAZs }\end{array}$ & 2 \\
\hline Positive & & Conflicts could arise & 1 \\
\hline Conservation Avoids Seabed damage & 23 & $\begin{array}{l}\text { Fishcombe Cove is on admiralty charts as } \\
\text { an anchorage }\end{array}$ & 1 \\
\hline Would adhere to VNAZs & 11 & VNAZs might scare tourists & 1 \\
\hline $\begin{array}{l}\text { Should enforce anchoring restrictions in } \\
\text { VNAZs }\end{array}$ & 1 & & \\
\hline Will alleviate some anchoring & 1 & & \\
\hline
\end{tabular}

